\title{
Thermal mapping of the 2009 dyke emplacement at Harrat Lunayyir, Saudi Arabia
}

\author{
Azizah Al Shehri ${ }^{1}$. Agust Gudmundsson ${ }^{1}$
}

Received: 13 June 2019 / Accepted: 4 September 2019 / Published online: 8 October 2019

(C) The Author(s) 2019

\begin{abstract}
The 2009 seismic episode at Harrat Lunayyir signalled a renewed geohazard and resulted in a regional dyke that propagated to a very shallow depth (a few hundred metres) below the surface. Since then, there has been an extensive research debate over the potential links between the volcanic/intrusive activity and tectonic processes, particularly because the earthquake swarm and dyke propagation did not eventually result in an eruption. The current study seeks to estimate the relative changes in surface temperatures as a means for detecting an impending dyke-fed eruption or, alternatively, dyke arrest at a shallow depth. An analysis of thermal (infrared) data with a focus on the spatial distribution of land surface temperatures over a longer period of observation may help reveal the link between volcanic activity and dyke propagation. Here, the land surface temperature changes in the centre of Harrat Lunayyir were recorded when the 2009 dyke was propagating toward the surface. The spatial distribution of the land surface temperatures in the area indicated the segmentation of the dyke and suggested the segments were arrested at somewhat different depths below the surface.
\end{abstract}

Keywords Dyke emplacement $\cdot$ Dyke arrest $\cdot$ Surface temperature $\cdot$ Volcanic hazard $\cdot$ Remote sensing

\section{Introduction}

Volcanoes pose a significant threat to human life and property through their extensive lava flow from effusive volcanic eruptions as well as pyroclastic flows and falls from explosive volcanic eruptions that altogether may create far-reaching hazards in the surrounding environment (Alberico et al. 2010). Considering the significance of these hazards, there has been extensive research over the past few decades aimed at exploring effective methods for the monitoring of volcanic activities (IUCN 2009). Monitoring systems are of great importance in terms of providing adequate warning of imminent potential disasters related to active volcanoes. Volcanic activity is usually controlled by processes that take place in the depths of the Earth's lithosphere, particularly in the magma reservoirs, and, thus, there are several challenges related to the monitoring of

Responsible Editor: Abdullah M. Al-Amri

Azizah Al Shehri

azizahzz@yahoo.com

1 Department of Earth Sciences, Royal Holloway University of London, Egham, UK active volcanoes and interpreting volcanic unrest episodes (Noguchi et al. 2011; Pyle et al. 2015; Al Shehri and Gudmundsson 2018; Gudmundsson 2019). Volcanic eruptions result in the transfer of heat from erupted lava flows and pyroclastic layers as well as from eruption columns that extend into the atmosphere. Additional environmental and tectonic processes associated with volcanoes include gas emission, earthquakes, and surface deformation (Harris 2013; Murphy et al. 2013; Noguchi et al. 2011; Pyle et al. 2015; Gudmundsson 2019).

The Red Sea Rift is one of the few areas in the world in which the processes of continental rifting and splitting actively take place and intraplate volcanism occurs, with a range of volcanic risk episodes observed in the western part over the last few decades (Bailey 2009; van der Zwan et al. 2013). The Red Sea Rift may be considered the most recent example of the early stages of ocean development via sea-floor spreading. This makes the areas within and adjacent to the rift particularly suitable for exploring volcanotectonic structures, dyke and fault patterns, and the inter-relation between structural, sedimentary, tectonic, and volcanic processes. Volcanic fields and dyke swarms formed along the eastern margin of the rift, predominantly during the Red Sea spreading as a result of a series of volcanic eruptions (Genna et al. 2002; Hansen et al. 2013a, b). 
One of the most recent and significant volcanotectonic episodes occurred in Harrat Lunayyir, a young basaltic lava field located in the northwestern part of Saudi Arabia and adjacent to the central part of the Red Sea in 2009. This volcanotectonic activity was primarily characterised by an intense earthquake swarm that occurred between April and June 2009, with more than 30,000 earthquakes taking place over the period of 3 months. It produced far-reaching consequences for the socioeconomic status of the region despite its limited direct damage and considering the area is quite remote and no eruption took place. As a result of the episode, the Saudi Arabian government had to evacuate 40,000 residents from the town of $\mathrm{Al}$ Ays, which is located in the path of lava flows from the potential volcanic fissure that would have formed if the dyke had reached the surface. The predominant interpretation based on both the earthquake data and geodetic data is that a near-vertical dyke of magma made its way from a great depth but then stopped at $\sim 2 \mathrm{~km}$ beneath the surface, which induced most of the earthquakes in the swarm (Jónsson et al. 2010). More recent studies, however, conclude that the dyke became arrested at much shallower depths, namely, several hundred metres below the surface, indicating a significantly greater hazard than previously estimated (Al Shehri and Gudmundsson 2018). The arrest of the dyke at a shallower depth is likely to be the factor in the observed tension fractures and normal fault formation at the surface. Another important research question behind why the dyke's movement was arrested at such a shallow depth - a topic analysed in many papers and of great interest and importance to volcanotectonic and hazard studies (e.g., Gudmundsson 2002, 2003).

In order to study the complex volcanic processes that lead to eruptions and other natural hazards as well as to monitor volcanic activities, remote sensing techniques have been extensively applied. Specifically, satellite images provide key data for understanding volcanic behaviour and registering thermal emissions from high-temperature events (Barnie and Oppenheimer 2015; Harris et al. 1997; Tralli et al. 2005). The fact that this data is acquired remotely makes these processes relatively risk-free, meaning this method is particularly wellsuited to studying the precursor signals of changing volcanic activity patterns. Additionally, thermal infrared (TIR) remote sensing of land surface temperature has been used in the past 20 years to monitor and explore volcanic processes and activity. TIR remote sensing is a significant tool in terms of mapping and monitoring the temperature of the surface; therefore, it could be used to identify increased volcanic activity by examining precursor signals (Haselwimmer and Prakash 2013; Realmuto and Worden 2000; Tralli et al. 2005; Vaughan et al. 2005). TIR data can provide a simultaneous and synchronous view of temperature changes in a given landscape, overcoming the limitations specific to meteorological or land-surveying data. Remote sensing TIR is generally used to monitor and map the surface temperature in various regions, as volcanic and other natural processes can release substantial amounts of heat. Therefore, the increase of volcanic activity signals can be both detected and measured with such types of technology and through the evaluation of precursor signals (Haselwimmer and Prakash 2013; Tralli et al. 2005; Vaughan et al. 2005). Nevertheless, recent studies have indicated a currently limited employment of TIR data due to the prevailing use of low-resolution satellite images (Sobrino et al. 2008). The present project addresses this phenomenon by using Landsat 7 satellite images, a split-window algorithm of land surface temperatures, and threshold methods for heat emission measurement (Fig. 1). Despite the disadvantages of Landsat 7, which has only one thermal band, this method of emissivity measurement meets the project objective of capturing surface temperature anomalies.

Thermal mapping based on satellite data is a valuable tool that produces a temporal and spatial interpretation of baseline thermal activity to identify thermal anomalies. Thermal mapping has been a common practice in the study of thermal patterns exhibited during volcanic eruptions (Ramsey and Flynn 2004). The primary advantage of this method is that it enables the retrieval of a greater number of spatial details. More conventional methods, such as meteorological monitoring, are characterised by a lack of a spatial dimension. A focus on spatiality is particularly important to this project since it aims to establish the relationship between the tectonic and volcanic components. A juxtaposition of thermal maps using the data from tectonic observations, also acquired through remote sensing, is hypothesised to be a suitable method for identifying any further relationships between these phenomena, thus addressing the research gaps discussed above.

This paper focuses on monitoring and estimating changes in surface temperature during the 2009 dyke emplacement in Harrat Lunayyir, Saudi Arabia, in order to examine how this method can be used to detect a potential dyke-fed eruption through significant temperature deviations. Overall, this method could provide critical information related to the support of disaster response and emergency management. The results also provide a foundation for response prioritisations and disaster assessment as well as informed mitigation planning and thorough risk assessments.

\section{Methodology}

The methodological framework employed in the current paper involved extending upon the recent research findings from the Harrat Lunayyir dyke emplacement episode by adding more extensive spatial components (Al-Amri and Fnais 2009; Baer and Hamiel 2010; Hansen et al., 2013; Al-Zahrani et al. 2013). First, the geological settings and hypotheses regarding volcanic and seismic activity in the area were reviewed to construct a basis for the empirical framework. Second, through the 
Fig. 1 a Satellite image (Landsat 7) identifying the area of interest. b Harrat Lunayyir borders
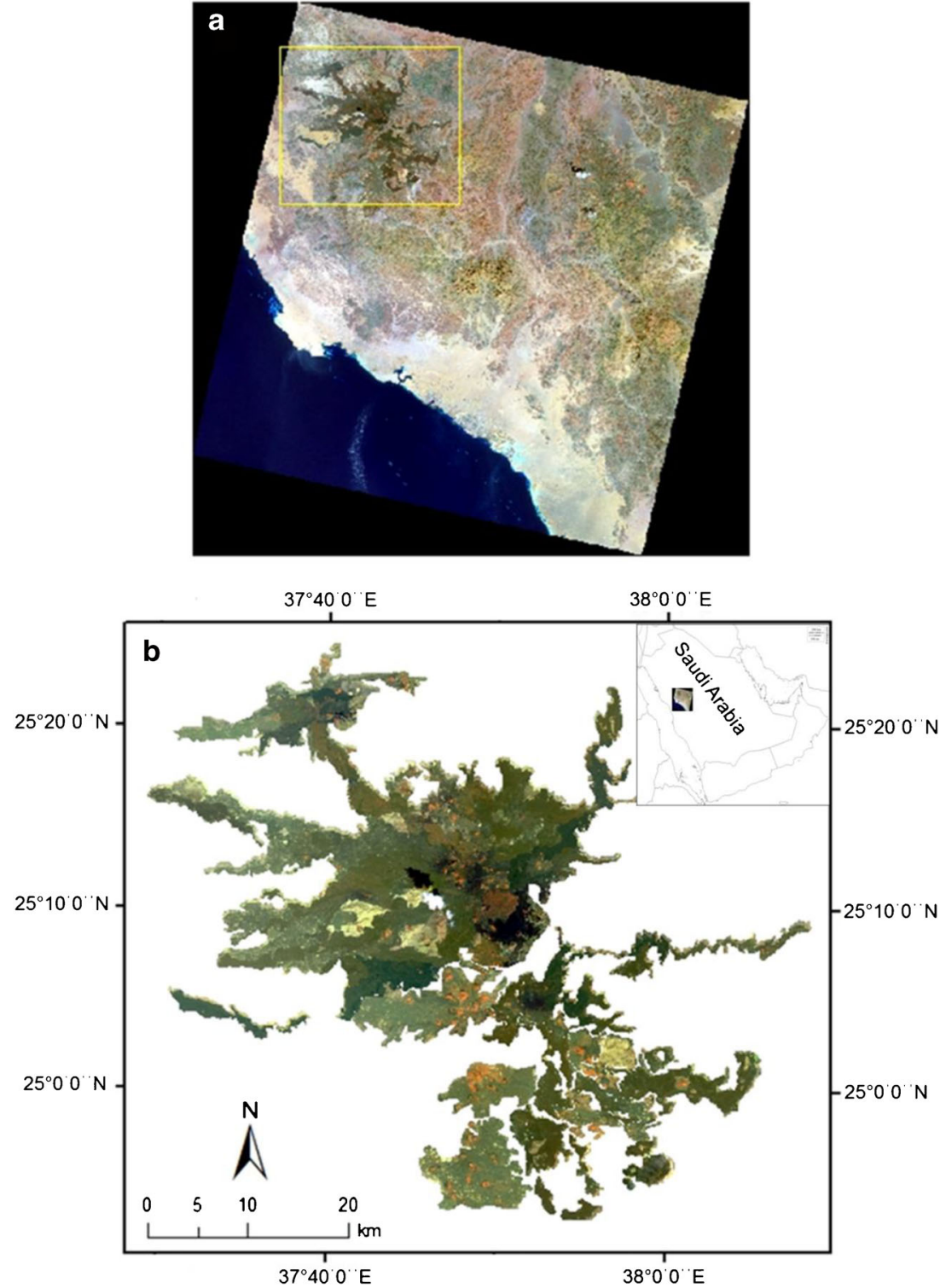

$37^{\circ} 40.0 \mathrm{E}$ processing of remote sensing data, the major spatial configurations of both volcanic and seismic processes were identified using spatial density mapping and spatial alignment. Third, thermal mapping was conducted based on Landsat 7 satellite images, which helped plot the distribution of heat anomalies across the periodical timescale. This allowed for the connection of the spatial density and alignment analysis findings to the land surface heat distribution patterns. The resulting surface temperature maps were then further related to the previous hypotheses about the 2009 dyke intrusion and analysed using spatial analysis techniques.

\section{Geological setting of Harrat Lunayyir}

In order to provide a methodology applicable to the scope of this project, the major geological and geomorphological characteristics of the area of interest were identified. Harrats, also known as Cenozoic basaltic lava fields, are commonly found in the Arabian Shield (Fig. 2). These fields are predominantly composed of alkali olivine basalt (Koulakov et al. 2014) and tholeiitic basalt (Al-Amri and Fnais 2009) lava flows. Harrat Lunayyir is located in the western region of the Arabian Plate and is composed of Neogene and Quaternary basaltic lava flows that cover the Neoproterozoic basement (Koulakov et al. 2014). Lunayyir is one of the youngest Harrats in the region, exhibiting a more diverse composition. According to studies conducted by Al-Amri et al. (2012), in terms of geostructural composition, Harrat Lunayyir is represented by two different basalt age groups: older Neogene basalts and younger Quaternary basalts (Fig. 2b). The Quaternary basaltic lava flows are common in the western region of the Arabian Shield and formed during the Red Sea spreading, which has been occurring since the Miocene period (Al-Amri and Al-Mogren 2011). The older Neogene basalts are characterised by scoria cones, 

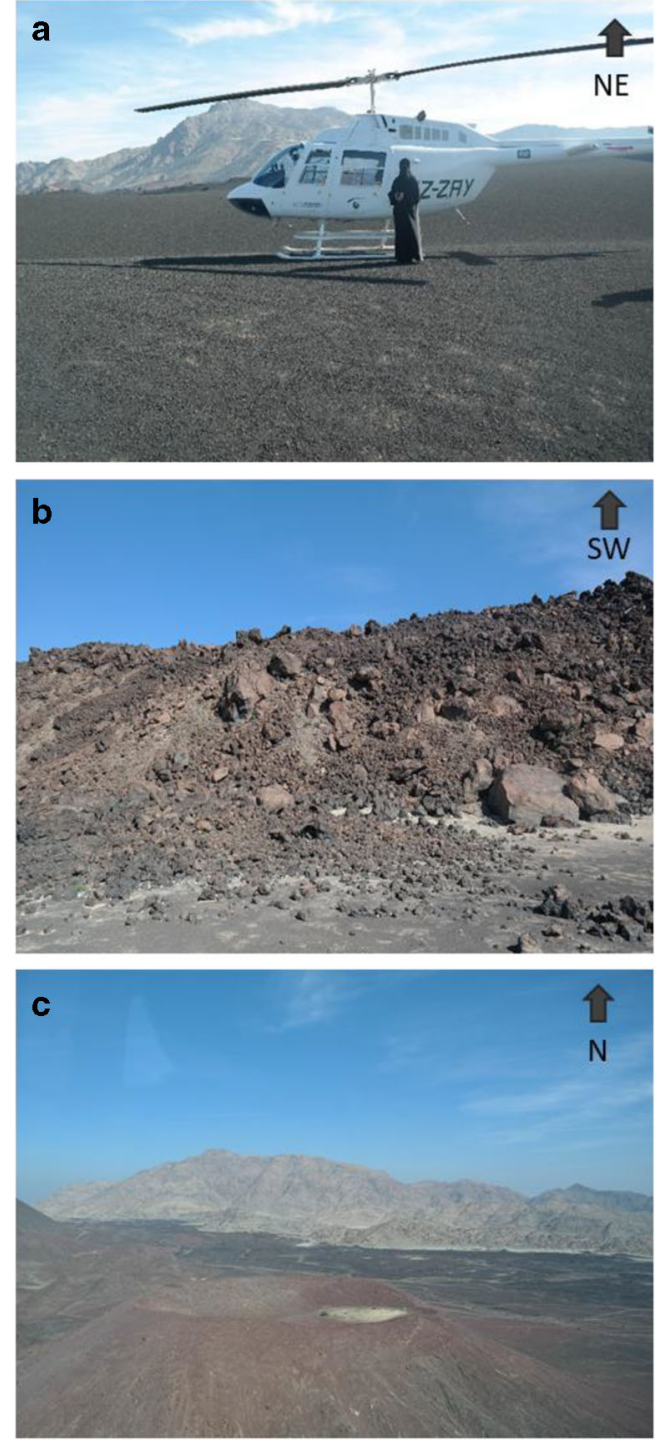

Fig. 2 Landscape features representing typical volcanic structures located in the southeastern part of the Harrat Lunayyir field. a Ground-level view of the volcanic scoria rocks in the northeast of Harrat Lunayyir (position: $\left.24^{\circ} 21^{\prime} 21.2^{\prime \prime} \mathrm{N} ; 39^{\circ} 46^{\prime} 55.3^{\prime \prime} \mathrm{E}\right)$. b Basaltic lava flows of the Quaternary age, southwestern part of Harrat Lunayyir (position: $24^{\circ} 12^{\prime} 9.1^{\prime \prime} \mathrm{N} ; 39^{\circ}$ $52^{\prime} 41.6^{\prime \prime}$ E) c Typical scoria cone with a cater formation, northern most part of the Harrat Lunayyir field (position: $24^{\circ} 23^{\prime} 4.5^{\prime \prime} \mathrm{N} ; 39^{\circ} 49^{\prime} 59.02^{\prime \prime}$ E, towards north)

which are significantly eroded to the extent of having indistinct crater formation (Fig. 2a). The basaltic layers rest directly on the Precambrian Arabian Shield (Al-Amri and Al-Mogren 2011; Al-Amri and Fnais 2009), while some Precambrian formations are also exposed in the central parts of the field. The volcanic deposits at Harrat Lunayyir are not radiometrically dated, although a number of studies have indicated a possible eruption that occurred in the tenth century (Zobin et al. 2013). Moreover, signs of recent volcanic activity have been identified through the examination of the geomorphic features of the deposits, including pristine vent structures and unweathered lava surfaces (Pallister et al. 2010; Zobin et al. 2013).

\section{Dyke intrusion and other hypotheses}

The initial monitoring data obtained in the region demonstrated that the observed magmatic intrusion, or dyke propagation, was continuous throughout the earthquake swarm (Pallister et al. 2010). The bulk of research on these earthquake swarms and their associated surface deformation indicated that the primary surface deformation might be partly associated with dyke propagation at a shallow depth and that the earthquake epicentres resided beneath the morphologically young volcanic crater cones (Pallister et al. 2010). According to Mukhopadhyay et al. (2013), the vertical dyke propagation initiated at crustal depths and exhibited a 5-day peak period (15-20 May 2009). After this peak, the volcanic activity was seen to gradually diminish. During the intrusion process, the dyke propagated to more shallow crustal levels, which may have contributed to a portion of the meter-scale fault slip on the western graben-bounding faults (Mukhopadhyay et al. 2013; Pallister et al. 2010).

Zahran et al. (2009), relying on a range of geodetic monitoring data, registered seismotectonic observations

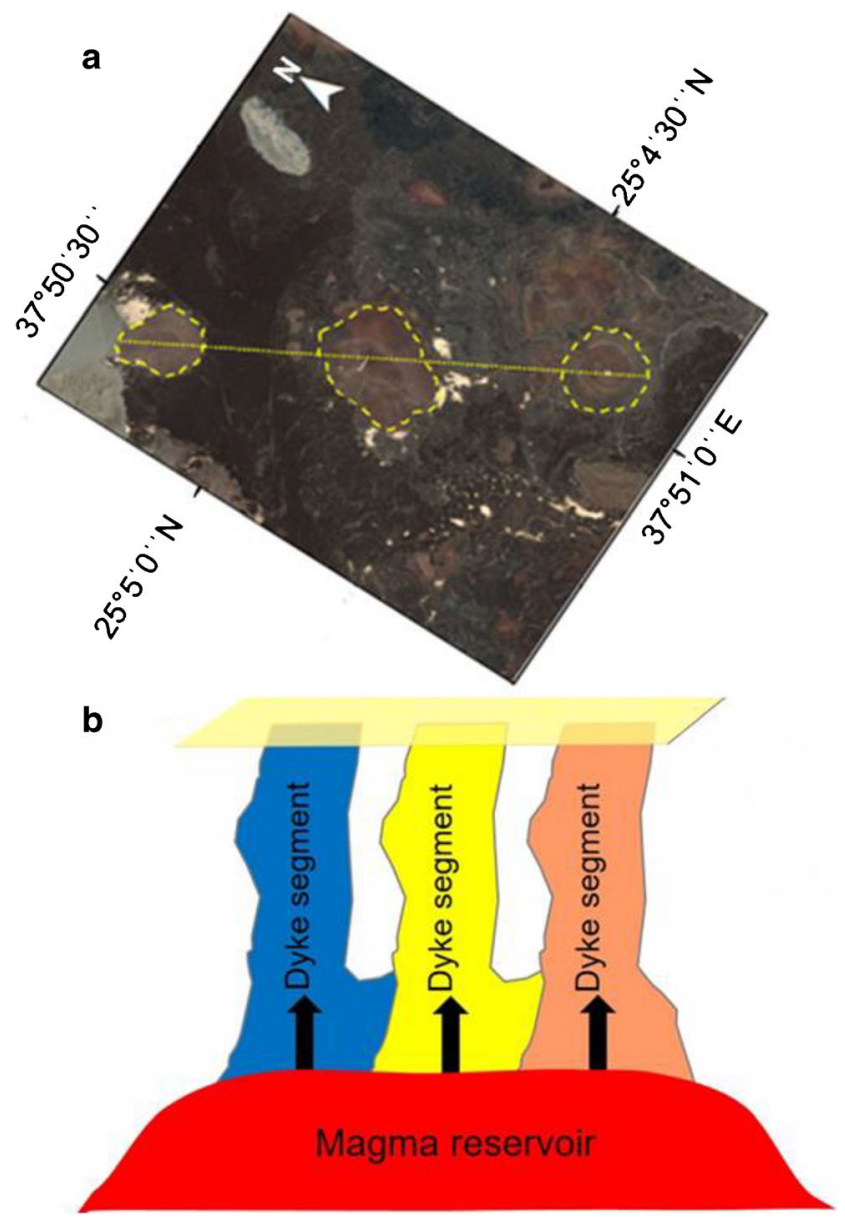

Fig. 3 a Data adopted from the Landsat satellite images of eruption points and centres developed by the segmented dyke. b Schematic representation of the possible feeder-dyke to the cinder cones in (a) 
Fig. 4 Harrat Lunayyir density map of monogenetic volcanoes/ eruption points. Around 104 eruption points are mapped; the majority of which are lava flows and cinder cones. The spatial alignments of volcanoes have also been plotted using the rose diagrams for data taken from the satellite images. The data plotted also show the zone of maximum density of vents

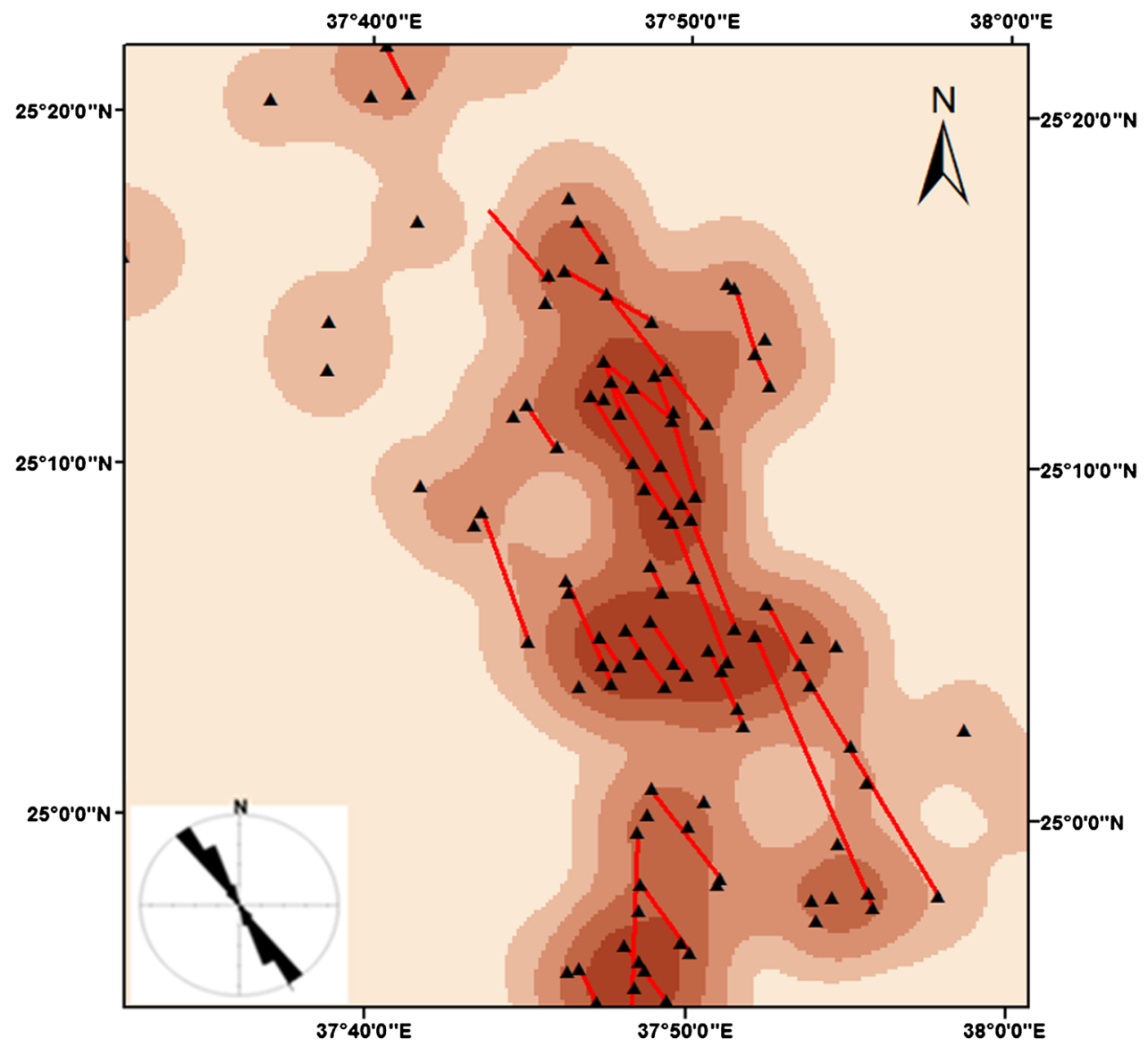

Eruptive vent density

$\left(/ \mathrm{km}^{2}\right)$

$0-0.02016$

$0.02017-0.06403$

$0.06404-0.1221$

$0.1222-0.1968$

$0.1969-0.3024$
Alignment of volcanoes
- volcanic vents

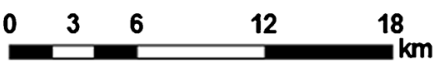

corroborating the dyke intrusion hypothesis. This data indicated that there was a $3-\mathrm{km}$-long surface rupture in the central area of the harrat, which had been extending prior to May 2009. InSAR data demonstrated that there was an uplift and $1-\mathrm{m}$ extension following the peak of the earthquake swarm, which corresponded to the first hypothesis, specifically in terms of stalled eruption, namely, an arrested dyke (Zahran et al. 2009). There are three major mechanisms through which dyke arrest occurs: stress barrier, elastic mismatch, and Cook-Gordon delamination (Gudmundsson 2011a, b, and 2019). The Cook-Gordon delamination mechanism implies that whatever contact that arrests the dyke is mechanically weak and has low tensile strength, so it opens up by the dyke-parallel tensile stress induced by the propagating dyke (Gudmundsson 2011a, b; Kavanagh et al. 2018). The opening of a contact is observed in many numerical models on dyke emplacement (Gudmundsson 2003, 2011a, 2019). When the dyke tip finally reaches the open contact, the tip becomes either deflected along the contact to form a sill or, alternatively, stops altogether (i.e., is arrested) (Gudmundsson 2003, 2011a).

Most dykes become arrested at various depths in the crust rather than ever reaching the surface (Gudmundsson 2002, 2003; Moran et al. 2011; Rivalta et al. 2015; Townsend et al. 2017) (Fig. 3). Previous models (Baer and Hamiel 2010; Pallister et al. 2010) have inferred that dyke intrusion is based on the fact that seismic events in the area tended to form a linear structure oriented toward the southern part of the harrat. In light of this, Koulakov et al. (2014) modelled the distributions of $\mathrm{P}$-wave to $\mathrm{S}$-wave velocities in the area and concluded that it is not possible to directly confirm whether the dyke intrusion took place in 2009. Based on their research and 
Fig. 5 Lineaments, mostly normal faults, in Harrat Lunayyir. The direction of the faults has also been plotted using the rose diagrams

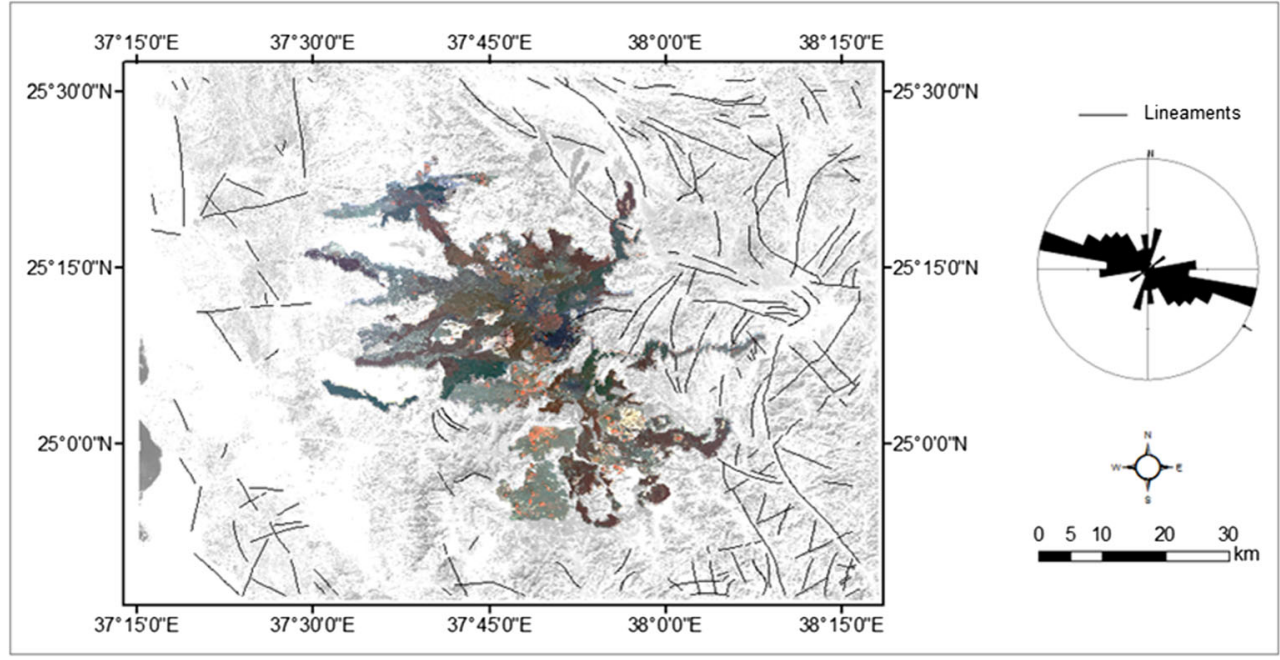

further attempts to develop seismic tomography models, an alternative hypothesis emerged, which assumes a buried fault may have caused the tectonic displacements that resulted in the linear structure of the events distribution (Koulakov et al. 2014). However, the earthquake swarm and thermal effects were more in-line with dyke emplacement, which is the model accepted by the present study and discussed in detail by $\mathrm{Al}$ Shehri and Gudmundsson (2018).

\section{Spatial density mapping}

Figure 4 shows the density map of 104 volcanic eruption points and volcanic vents, which have been identified and mapped. These are mostly crater, spatter, or cinder (scoria) cones, either existing alone or as parts of volcanic fissures or lava flows. Arc Map 10.1 was used to plot the volcanic vents, while the shape files of the volcanoes were imported into Arc
Map 10.1. With the aid of the density maps, the frequency of eruption centres could be assessed in the neighbourhood surrounding each raster cell. Specifically, the neighbourhood is the area around each cell centre and the total of all eruption points divided by the total area of the neighbourhood.

The spatial density map was drawn with the help of ArcGIS 10.1 , has a radius of approximately $18.5 \mathrm{~km}$, and focuses on producing a generalised output raster. The addition of lineaments (e.g., proposed volcanic fissures) in this map took place with the help of Harrat Lunayyir raster images. There is an evident clustering of eruption points and vents, as indicated by the contours (Fig. 4). In addition, it has been suggested that a number of eruption points and crater cones form parts of volcanic fissures whose northwest trend is the same as that of the proposed 2009 dyke. The major density subzone present in the central area of Harrat Lunayyir is mostly composed of lava shields and scoria cones, which majorly contribution to
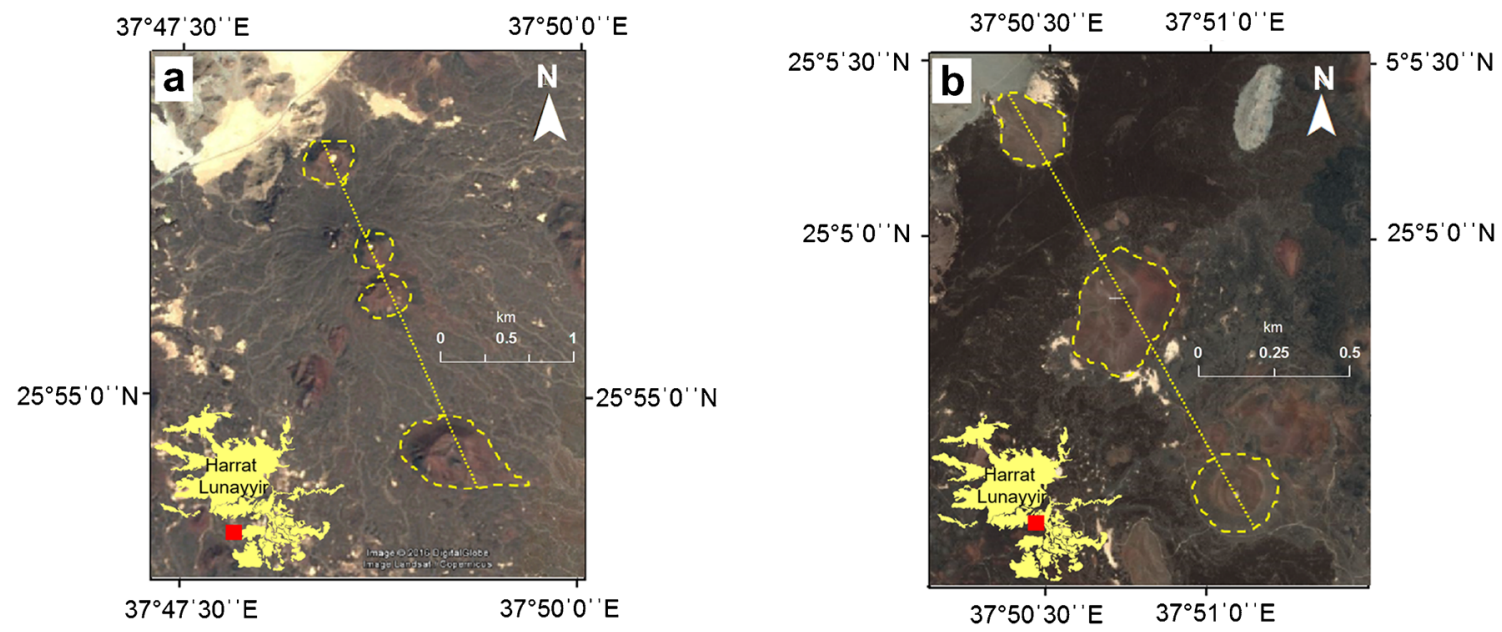

Fig. 6 Landsat 7 satellite images showing the spatial alignment of eruption points/monogenetic volcanoes in the central part of Harrat Lunayyir. The crater cones are presumably fed by a dyke. The maps also provide the location of the volcanic eruptions 


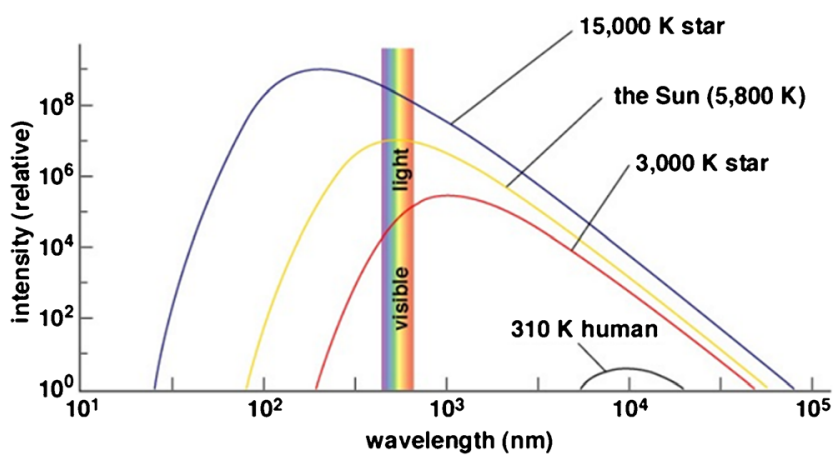

Fig. 7 The thermal radiation emitted by several reference objects. Hotter objects have smaller peak wave lengths and sharper curves (Wellons 2007)

eruption sites. The figure also shows that the lowest eruption point frequency is concentrated in the form of a cluster in the southwestern region.

\section{Spatial alignment of volcanic eruptions}

Volcanic vent alignment is evident in the assessed satellite imagery, which exhibits at least three volcanic cones traced on ArcGlobe 10.1 and saved in polyline shape files (.shp). These files were exported into ArcGIS 10.1 and juxtaposed with the lineament's locations (Fig. 4). Identification of the alignments was based on the Hough transform method algorithm and automatically calculated using the geosimulation capacity of the software. The algorithm behind this method is based on the transformation of the linear data in a Cartesian plane into points in a parameter plane, calculating the length and angle between any line of vent alignment origin and the coordinate system. Each alignment is marked by orientation, length, and edge coordinates. The volcanic fissures, which were inferred from the volcanic alignments, have also been highlighted (Figs. 5 and 6). When more than one configuration is possible, the elongated caters can be used to highlight the general inferred fissure trend, following a standard method (Paulsen and Wilson 2009). The strikes of the elongated vents then coincide with corresponding strikes of the volcanic

Table 1 Metadata and acquisition dates of Landsat 7

\begin{tabular}{lllll}
\hline Acquisition date & Satellite/sensor & Path & Band & Spatial resolution \\
\hline 17 March 2007 & Landsat ETM+ & 147 & 6 & $60 \mathrm{~m}$ \\
03 March 2008 & Landsat ETM+ & 147 & 6 & $60 \mathrm{~m}$ \\
22 March 2009 & Landsat ETM+ & 147 & 6 & $60 \mathrm{~m}$ \\
26 June 2009 & Landsat ETM+ & 147 & 6 & $60 \mathrm{~m}$ \\
23 July 2009 & Landsat ETM+ & 147 & 6 & $60 \mathrm{~m}$ \\
26 August 2009 & Landsat ETM+ & 147 & 6 & $60 \mathrm{~m}$ \\
25 March 2010 & Landsat ETM+ & 147 & 6 & $60 \mathrm{~m}$ \\
12 March 2011 & Landsat ETM+ & 147 & 6 & $60 \mathrm{~m}$ \\
\hline
\end{tabular}

fissure. Using the GEOrient software, rose diagrams could also be produced, which helped identify the volcanic fissures in the NNE-SSW or NNW-SSE trends that dominate the volcanic region along with the presence of some small subsets like the N-S subsets.

The rose diagram of around 84 tension fractures and normal faults associated with the dyke-induced earthquake swarm in 2009 (Al-Zahrani et al. 2013) are also shown in Fig. 5. In terms of the two main sets of fracture strikes, the main strikes NNW-SSE, whereas the smaller one strikes NNE-SSW.

\section{Thermal mapping of Harrat Lunayyir}

Thermal infrared (TIR) technology is a remote sensing approach that has been utilised to evaluate the surface temperature of targeted regions as well as to monitor and investigate volcanotectonic events, volcanic eruptions, intrusions, and any associated earthquakes and tremors. Satellite images have major potential to gain more information about volcanic eruptions and the behavioural aspects related to such natural phenomena. In addition, the investigation and observation of thermal energy emissions from high-temperature events such as eruptions or shallow intrusions are also considered to be of paramount significance in this field (Barnie and Oppenheimer 2015; Harris et al. 1997; Tralli et al. 2005).

Thermal infrared (TIR) technology is a remote sensing approach that has been utilised to evaluate the surface temperature of targeted regions as well as to monitor and investigate volcanotectonic events, volcanic eruptions, intrusions, and any associated earthquakes and tremors. TIR has been an operational standard for the past 20 years. Generally speaking, thermal energy in the infrared band is emitted from each object at a temperature above absolute zero. Thus, vegetation, soil, rock, water, and living beings emit infrared bandbased thermal and electromagnetic radiation, which can in turn be measured and evaluated using infrared energy emission-detection sensors. The human eye is incapable of detecting any measurement or change in thermal energy emissions in the infrared energy band, as it can only detect light beams in the 400- to 700-nm range and remains sensitive only within this spectrum. Moreover, the sensitivity of the human eye is generally restricted to the infrared reflective index range of $700 \mathrm{~nm}-3.0 \mu \mathrm{m}$ and the infrared energy range of 3.0-14 $\mu \mathrm{m}$ (Jensen 2007). Thus, it is not possible for the human eye to process the reflective infrared band or thermal energy emanating in the infrared spectrum (Fig. 7).

Some satellites have sensors for the purpose of heat detection, such as Landsat TM/ETM, NOAA AVHRR ASTER, and MODIS. The current study employed the Landsat 7 series with a ETM+ sensor (Table 1) to derive thermal bands related to Landsat and land surface temperatures (LST), such as band 
Table 2 ETM+ thermal band calibration constants (NASA 2018)
Constant $1-K 1\left(\right.$ watts $\left./\left(\mathrm{m}^{2} \times \mathrm{sr} \times \mu \mathrm{m}\right)\right)$

Constant $2-K 2$ (Kelvin)

\begin{tabular}{lrr}
\hline Landsat 7 & 666.09 & 1282.71
\end{tabular}

6 from ETM+, for various durations. The objectives of this Harrat Lunayyir-based study resulted in the obtainment of three different images from the USGS server (earthexplorer. usgs.gov), which could be further identified using ERDAS IMAGINE 2015 and ArcGIS 10.1 software. These two approaches have been utilised to help understand the collected surface temperature data.

The downloaded bands are part of the thermal bands, specifically band 6 of ETM+. The bands of ETM+ and those of dataset band 6 are generally favoured owing to their enhanced brightness, which can help facilitate the study of this region via photographs. This region is devoid of any significant vegetation cover, and the metadata of the thermal bands is generally used to determine the rows, axis, and thermal constants related to such developments in the region.

\section{Theoretical basis for the method}

\section{Conversion to radiance}

Landsat thermal data is transformed into a set of mosaic images, and then any obtained digital numbers can be transformed into LST (land surface temperature) values through any method used for radiometric modifications and corrections. The data is generated in a manner that allows for a comparison with the previously available data (Table 1). The radiance of the sensors, which is related to the regions of the wavelength, can then be preserved and stored within the collected and compared digital numbers (DNs). These DNs can then be quantified through the utilisation of systems that have been specifically designed for such purposes. The primary benefits of this involve both the processing and storage of data. The absence of physical units or other such information associated with DN-based values means that such values need to be converted into tangible radiances.

The resulting values of ETM+ DN, which is a specific formula utilised for the purpose of converting the DNs into spectral radiance measures, will generally fall between 0 and 255.

$L_{\lambda}=$ Grescale $\times$ Qcal + Brescale

This can also be designated as follows:

$$
L_{2} \equiv \frac{\left(\mathrm{MAX}_{2}-\mathrm{LMIN}_{2}\right)}{(Q C A L M A X-Q C A L M I N) \times(Q C A L-Q C A L M I N)+\text { MIN }_{2}}
$$

Here $Q$ cal is the quantified calibrated pixel value in DN, $L M I N \lambda$ is the spectral radiance scaled to QCALMIN in $\left(\mathrm{W} /\left(\mathrm{m}^{2} \times \mathrm{sr} \times \mu \mathrm{m}\right)\right), \mathrm{LMAX} \lambda$ is the spectral radiance scaled to QCALMAX in $\left(\mathrm{W} /\left(\mathrm{m}^{2} \times \mathrm{sr} \times \mu \mathrm{m}\right)\right)$, QCALMIN is the minimum quantised calibrated pixel value (corresponding to $L M I N \lambda$ ) in DN, QCALMAX is the maximum quantised calibrated pixel value (corresponding to $L M A X \lambda$ ) in $\mathrm{DN}=255$ (NASA 2018).

\section{Conversion from spectral radiance to temperature}

Landsat ETM+ Band 6 imagery can be transformed and altered to become more effective than spectral radiance or brightness temperature. On the assumption of unity emissivity, such imagery can be effectively utilised to evaluate Earthatmosphere system temperatures obtained by satellites. The formula of transformation and conversion is as follows:

$$
T=\frac{K 2}{\operatorname{In}\left(\frac{K 1}{L_{\lambda}}+1\right)}
$$

where $T$ is the effective at-satellite temperature in Kelvin, $K 1$ and $K 2$ are calibration constants, and $L_{\lambda}$ is the spectral radiance as defined in Eq. 2 (Table 2) (NASA 2018).

\section{Conversion from degrees Kelvin to degrees Celsius}

Since the temperature will be estimated in degrees Celsius, the results obtained from Eq. 3 can be converted into degrees Celsius. The formula-based method for such a conversion can be described using the formula B6-273.15. Here, B6 is the result obtained from Eq. 2, which is expressed in degrees Kelvin. In this manner, the temperature outline map can be inferred and developed.

\section{Heat transfer model}

The heat transferred via electromagnetic radiation is referred to as 'thermal radiation'. Infrared radiation is a sub-category of thermal radiation and can also transfer heat; consequently, it is frequently referred to as 'heat radiation'. However, only a fraction of the infrared radiation spectrum is actually able to carry heat (Wellons 2007; Da Wen 2010). While all matter with a temperature greater than $0^{\circ} \mathrm{K}$ (absolute zero) will emit electromagnetic radiation, either the radiant flux density or the rate of energy flow per unit area and the spectral composition of this radiation is dependent upon the temperature of the 

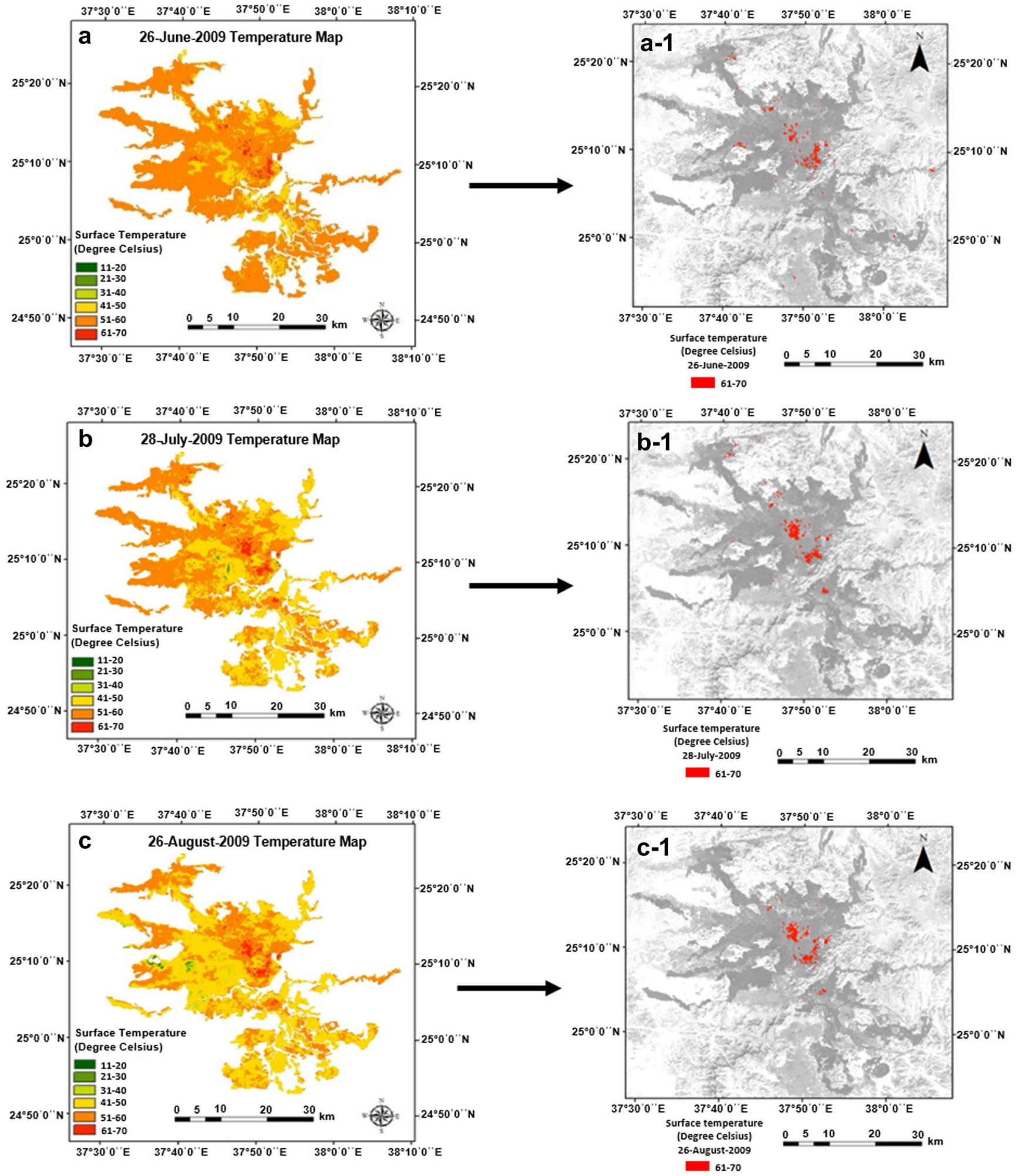

Fig. 82009 surface temperature map in degree Celsius. a-c Absolute temperature plots for the whole region during June, July, and August 2009. The red colour in (a-1, b-1, and c-1) highlights the anomalously hot regions

emitting matter (Blackett 2017). Thermal radiation is also capable of directly transferring heat over long distances (e.g., the Earth continuously receives thermal radiation from the Sun).
As a consequence of the wave nature of radiation and the Earth's atmosphere, a proportion of the energy received will be reflected back, while some may be transmitted further and 


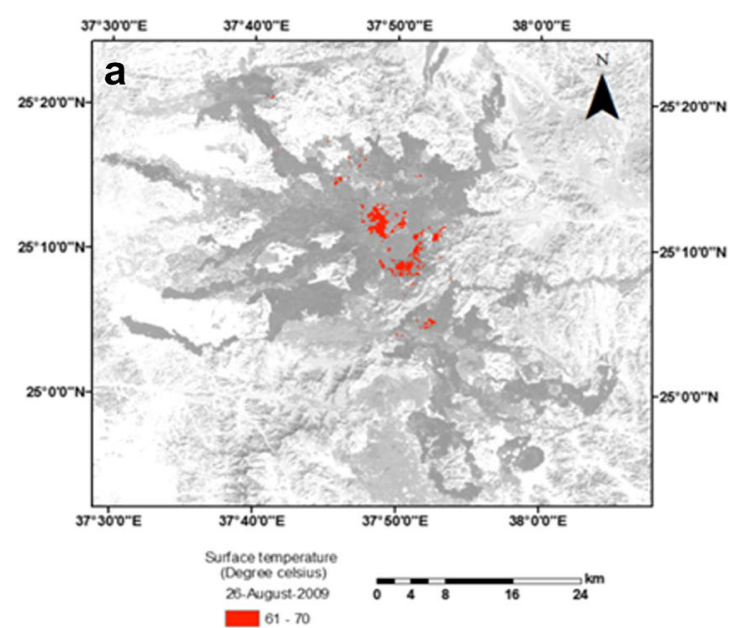

Fig. 9 a August 2009 surface temperature map in degree Celsius; the red colour indicates the temperature. b Unsupervised classification of Harrat Lunayyir lava flows (Al Shehri and Gudmundsson 2019). You can see the

the remainder absorbed. Only the latter results in the direct heating of the matter. The percentage of reflected, absorbed, and transmitted heat is dependent on the nature of the matter, the surface characteristics of the matter, and the wavelength of the incipient radiation (Da Wen 2010). The Stefan-Boltzmann law states that the radiant flux density generated by an object is directly proportional to the fourth power of that object's

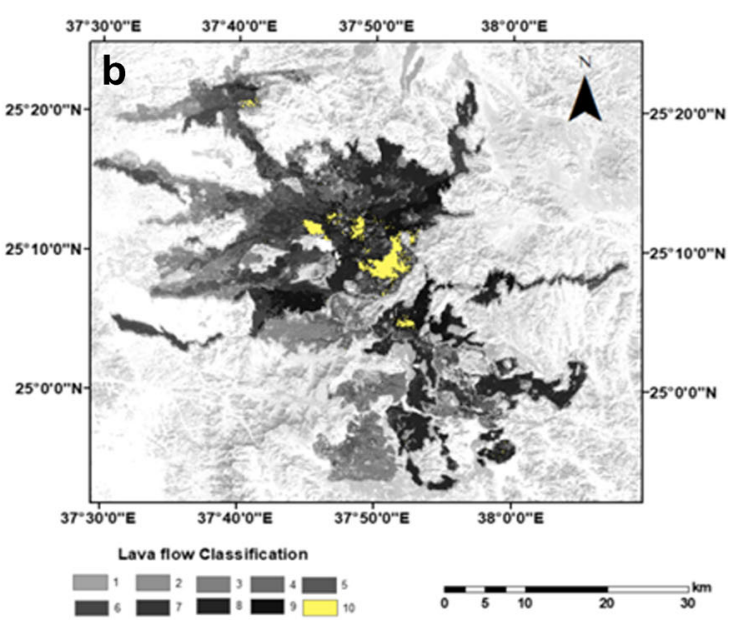

location of the high surface temperature ' $a$ ' located in the same area of new lava flow ' $b$. class 10 '

surface temperature (Boya 2004) (i.e. the greater the temperature of an object, the greater the total energy it will emit).

Temperatures associated with volcanic features are subject to wide variations. While newly erupted basaltic lavas may have a temperature range of 1050 to $1200^{\circ} \mathrm{C}$ for basaltic lavas and komatiite may be as high as $1600{ }^{\circ} \mathrm{C}$ (Gudmundsson 2019), the temperatures associated with lava lakes can be as
Fig. 10 a Reflectance spectrum of the old and young lava flows. $\mathbf{b}$ An old lava flow affected by significant surface oxidation attains high reflectance values in the near infrared region. $\mathbf{c} \mathrm{A}$ typical Quaternary basaltic lava flow (Upper Maqrah) (Al Shehri and Gudmundsson 2019)
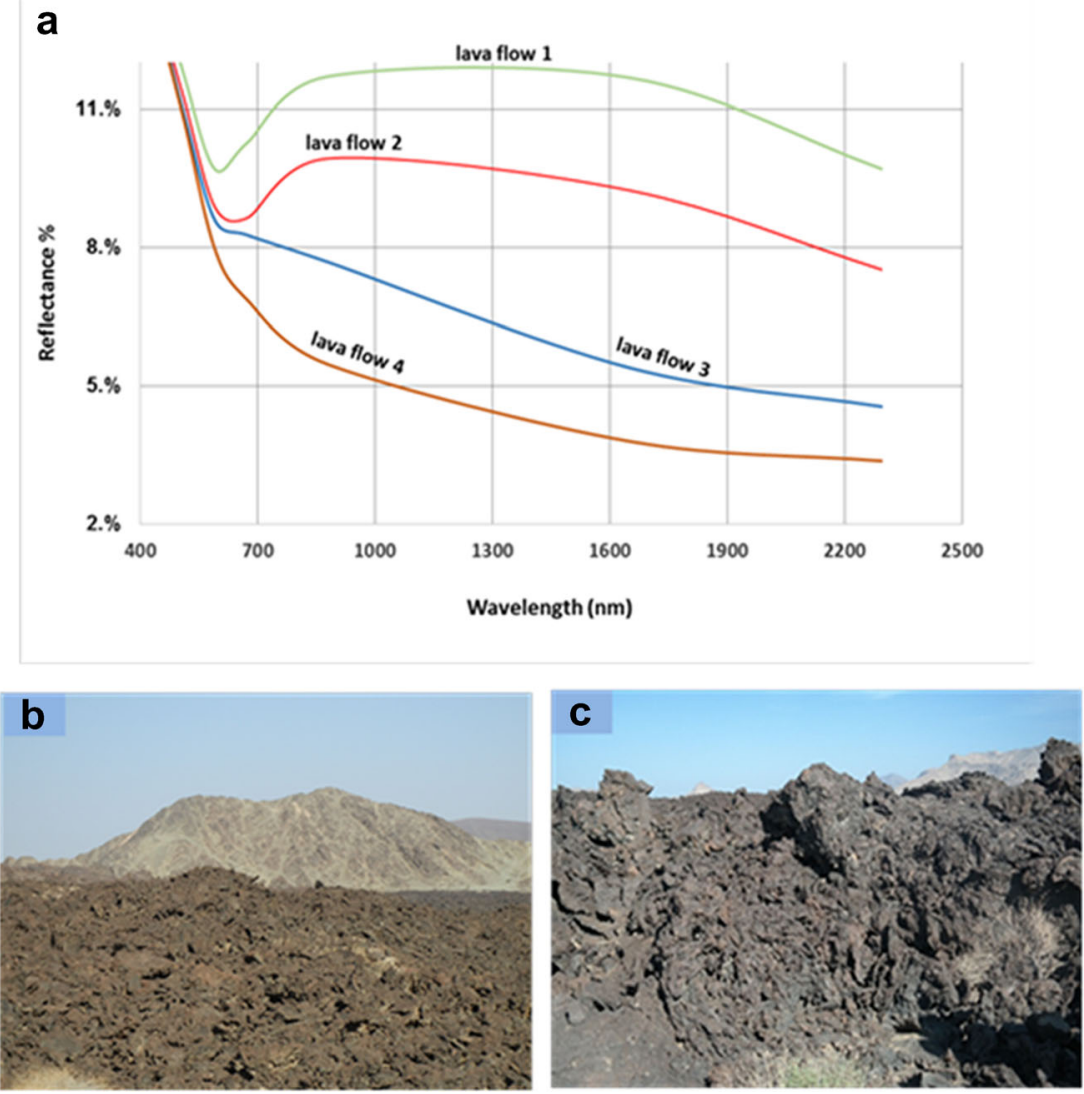
Table 3 Mean temperatures from grids

\begin{tabular}{lccccc}
\hline $\begin{array}{l}\text { Month/ } \\
\text { year }\end{array}$ & 2007 & 2008 & 2009 & 2010 & 2011 \\
\hline March & 35.7 & 37.4 & 42.8 & 40.3 & 36.6 \\
June & & & 58.4 & & \\
July & & & 55.5 & & \\
August & & 49.5 & 47.7 & & \\
December & 38.9 & & & & \\
\hline
\end{tabular}

high as $1473{ }^{\circ} \mathrm{C}$, and cooler active surfaces may only reach $673^{\circ} \mathrm{C}$ (Oppenheimer and Yirgu 2002. At such temperatures, the primary radiant emissions are derived from the thermal infrared (TIR), middle infrared (MIR), and shortwave infrared (SWIR) regions of the electromagnetic spectrum.

\section{Results}

Volcanotectonic signals indicative of a potential dyke-fed eruption in Harrat Lunayyir commenced on 18 April 2009, peaked between 17 and 19 May, and ended in July that same year (Baer and Hamiel 2010; Koulakov et al. 2014; Pallister et al. 2010; Al Shehri and Gudmundsson 2018). The dyke eventually became arrested at a few hundred metres below the ground surface, with the dyke's top section thickness estimated to be between 6 and $12 \mathrm{~m}$ (Al Shehri and Gudmundsson 2018). The strike-dimension (e.g., horizontal length) of the dyke was estimated to be $14 \mathrm{~km}$, giving a length/ thickness ratio of between 2400 and 1200, a common value for regional dykes.

For the thermal monitoring and modelling of the arrested dyke, the digital number (DN) values from the image were converted to a radiance value and then into degrees Celsius. Thermal maps for March, June, July, and August 2009 were prepared in order to monitor the progress associated with temperature increases. It is important to note that the temperatures of $60-70{ }^{\circ} \mathrm{C}$ in June, July, and August 2009 (Fig. 8) were detected in a region of young lava flow. The lavas were also mostly vesicular and porous. Climatic conditions impacted

Table 4 Mean monthly surface air temperature, Harrat Lunayyir

\begin{tabular}{llllll}
\hline Month/year & 2007 & 2008 & 2009 & 2010 & 2011 \\
\hline March & 22.2 & 25.1 & 22.7 & 25.6 & 23.6 \\
June & 29.7 & 31.1 & 30.9 & 32.5 & 31.2 \\
July & 31.9 & 31.8 & 32 & 32.8 & 32.5 \\
August & 32.6 & 31.8 & 32.2 & 34.5 & 31.9 \\
December & 22.2 & 22.4 & 21.9 & 23 & 21.9 \\
\hline
\end{tabular}

surface weathering and, consequently, the texture of the lava flows. Lava on Harrat Lunayyir was subject to various kinds of surface alteration, such as chemical oxidation caused by weathering. Spectral reflectance measurements of the basaltic lava flow on Harrat Lunayyir were taken, and lava flow surfaces of varying ages were subject to methodical measurement via Landsat 8 over the range $435-2300 \mathrm{~nm}$ (Al Shehri and Gudmundsson 2019). Young lava exhibited reflectance values of approximately $4 \%$ as a consequence of minimal weathering, which indicated that a small proportion of the radiation was reflected, while some were transmitted, and the remainder was absorbed. However, only the absorbed energy is relevant to the heating of the lava flow units (Figs. 9 and 10).

The temperature anomalies were identified based on the normalisation of the neighbourhood pixel brightness values. First, the baseline surface temperature series data, which included averages of the characteristics displayed by the pixel during the 5-year period of observation (2007-2012), were estimated and georeferenced for given mapping units. This helped identify the statistical threshold for the brightness values for the given neighbourhood of pixels. Second, the resulting series was obtained by dividing the central values in the normalised series. Based on this calculation, the acquired surface temperature distribution values were treated as anomalous if they exceeded $60.7^{\circ}$.

The mapped surface temperature measurements of around 51-60 ${ }^{\circ} \mathrm{C}$ obtained in March were found to be highly variable throughout the years 2007, 2008, 2009, 2010, and 2011 (Tables 3 and 4; Fig. 11). However, this was not indicative of an absence of seismic swarm in 2007, in October 2007, a volcanotectonic episode in the region commenced and was typified by an earthquake swarm (Al-Amri and Al-Mogren 2011; Mukhopadhyay et al. 2013; Zobin et al. 2013). Additionally, a swarm of more than 500 earthquakes began in October 2007 and ended in May 2008, indicating an origin with a NW-SE strike at a depth greater than $10 \mathrm{~km}$. No surface deformation was correlated with this occurrence $(\mathrm{Xu}$ et al. 2016).

However, the seismic swarm that occurred from October 2007 to May 2008 may be considered a precursor to the main swarm that occurred during the dyke emplacement between April and July 2009. This precursor swarm has been interpreted as a deep-seated reservoir subject to inflation and potential rupture (Koulakov et al., 2015). During reservoir inflation, the reactivation of fractures, especially faults in the reservoir roof, would typically result in earthquakes. Furthermore, in regard to the swarm of 2009, the extent of coverage increased toward the northern portion of the Harrat and there are other inferred segments of the dyke. It is therefore anticipated that a number of other dyke areas will assume the same direction as the 2009 extinction fracture; however, all such areas have been arrested at different sub-surface depths (Fig. 12c). 

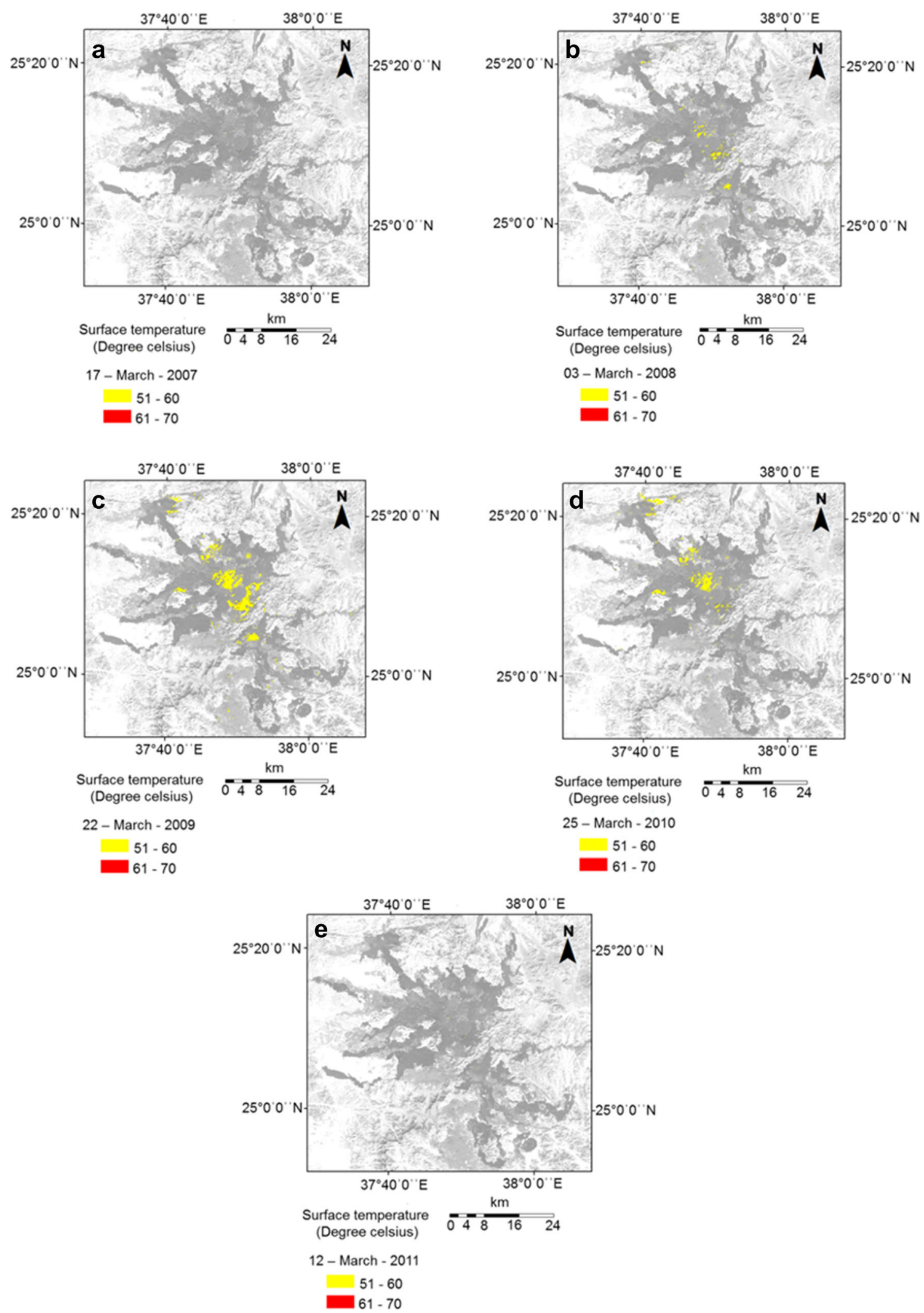

Fig. 11 March 2007, 2008, 2009, 2010, and 2011 surface temperature maps (degree Celsius); the yellow colour indicates the temperature anomalies

To achieve a more comprehensive presentation of the spatial-temporal distribution of LST for several subsequent periods (using the month March of each subsequent year), Fig. 11 reveals the range of the temperature 

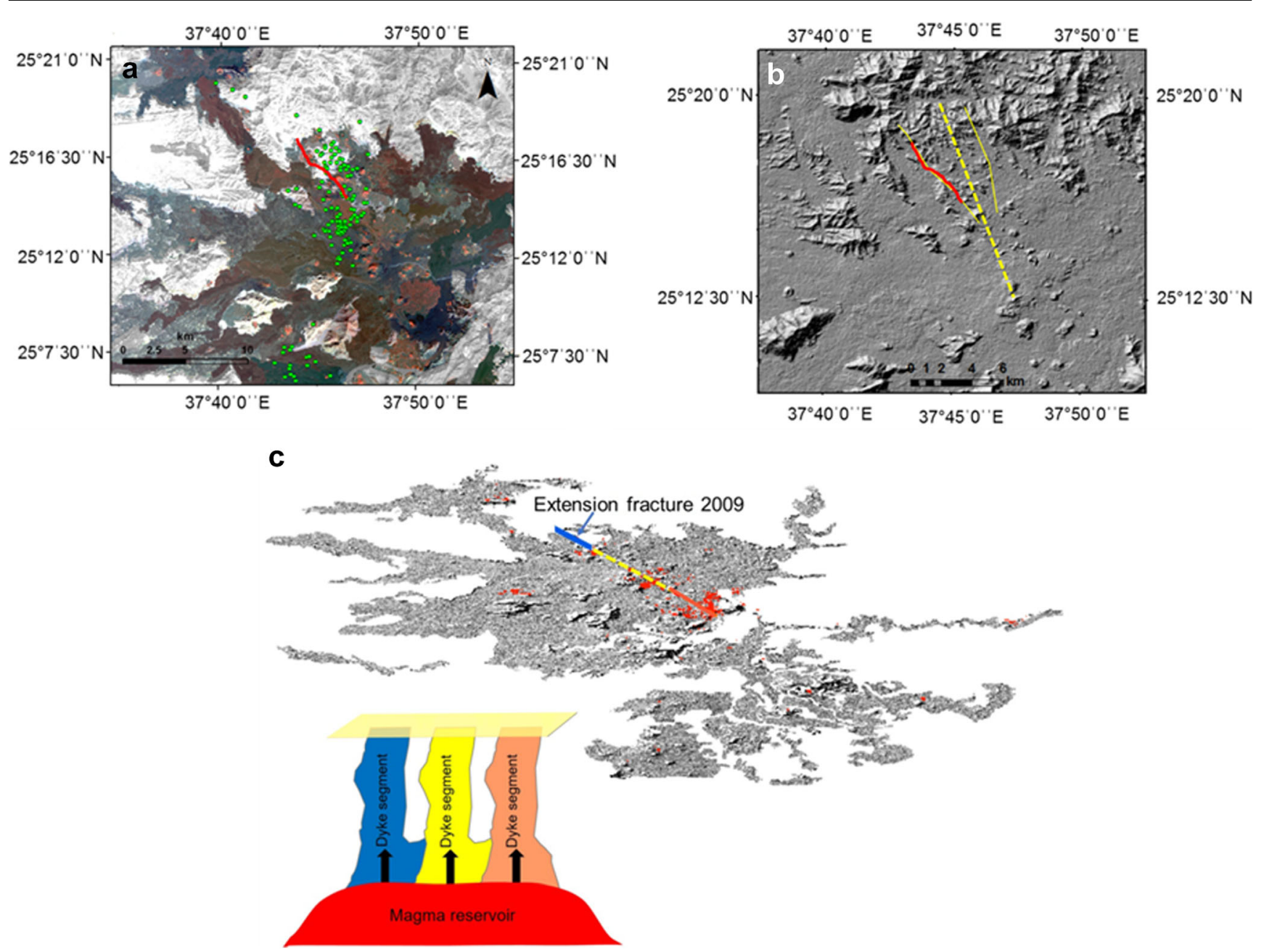

Fig. 12 Landsat 7 image of Harrat Lunayyir. a From the SGS website, the probable epicentre locations for the 7 May-15 August 2009 seismic events are shown as green circles, whereas the extension fracture is represented by a red line. $\mathbf{b}$ The dashed yellow line represents the projection

over the Harrat Lunayyir range- from 51 to $60{ }^{\circ} \mathrm{C}$. The high temperature coincides with areas of maximum tectonic deformation (e.g., extensive fracture formation) (Fig. 12). Spatial density analysis and LST revealed that heat emission spikes can be observed throughout the years regardless of whether earthquakes, or any sort of seismic activity, had occurred or not. However, there is a statistically significant correlation between the density of heat and the seismic period timescale.

The analysis of the tectonic processes over the same periods of observation reveals insignificant levels of correlation between the surface temperatures and seismic intensity. The main cluster of seismic intensity formed in the southwestern part of the Harrat Lunayyir was not linked to any post- or pre-activity temperature increase. The epicentre locations reveal the general direction of the fracturing process toward the northern central area, which is in-line with previous research results (Pallister line of the dyke direction at depth (modified after Baer and Hamiel 2010; Pallister et al. 2010); the red and yellow solid lines are the projections of the other inferred segments of the dyke. c Dyke segments arrested at different depths along the extension fracture of 2009

et al. 2010). Notably, the cluster of temperature anomalies in the southern central part were seen to have intensified in the period following the earthquake swarm. These patterns most likely reflect the emplacement of a very shallow dyke intrusion.

\section{Discussion}

TA thorough interpretation of the heat anomalies and variability in land surface temperature based on the remote sensing data is limited due to certain other factors (geothermal, hydrothermal, and geomorphological) behind temperature variations as well as characteristics of the remote sensing data. Hence, there are a number of factors that must be taken into account when acquiring and analysing thermal maps. These factors include the following: 


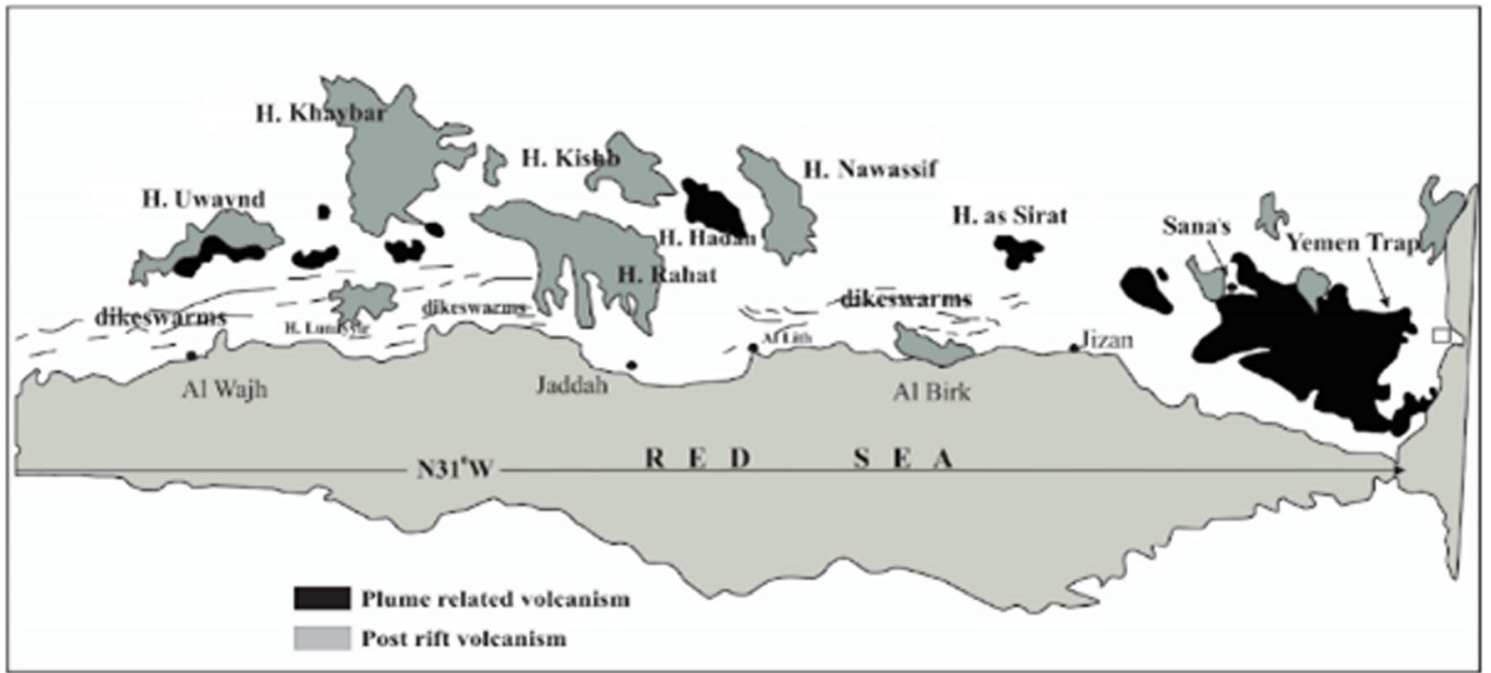

Fig. 13 Map of the geothermal system of the Red Sea Rift area (Chandrasekharam et al. 2016)

1. Spatial resolution. The TIR band of the ETM+ satellite sensor has a spatial resolution of $60 \mathrm{~m}$, whereas the other six multispectral bands have a spatial resolution of $30 \mathrm{~m}$, and the panchromatic band (or band 8) has a spatial resolution of $15 \mathrm{~m}$ (Galiano et al. 2011). A major difficulty commonly encountered in evaluating the accuracy of thermal surveys is the disparity between the spatial scale of the remote sensing measurements and contemporaneous ground truth measurements (Vlassova et al. 2014).

2. Atmospheric effects. Further research should be directed toward the incorporation of InSAR and other methods of atmospheric correction into volcanic activity monitoring systems that use remote sensing data. Additional complications related to aerial or orbital measurements of surface radiance to actual surface
Fig. 14 The map of the hot water wells identified over the period of observation (2007-2011)

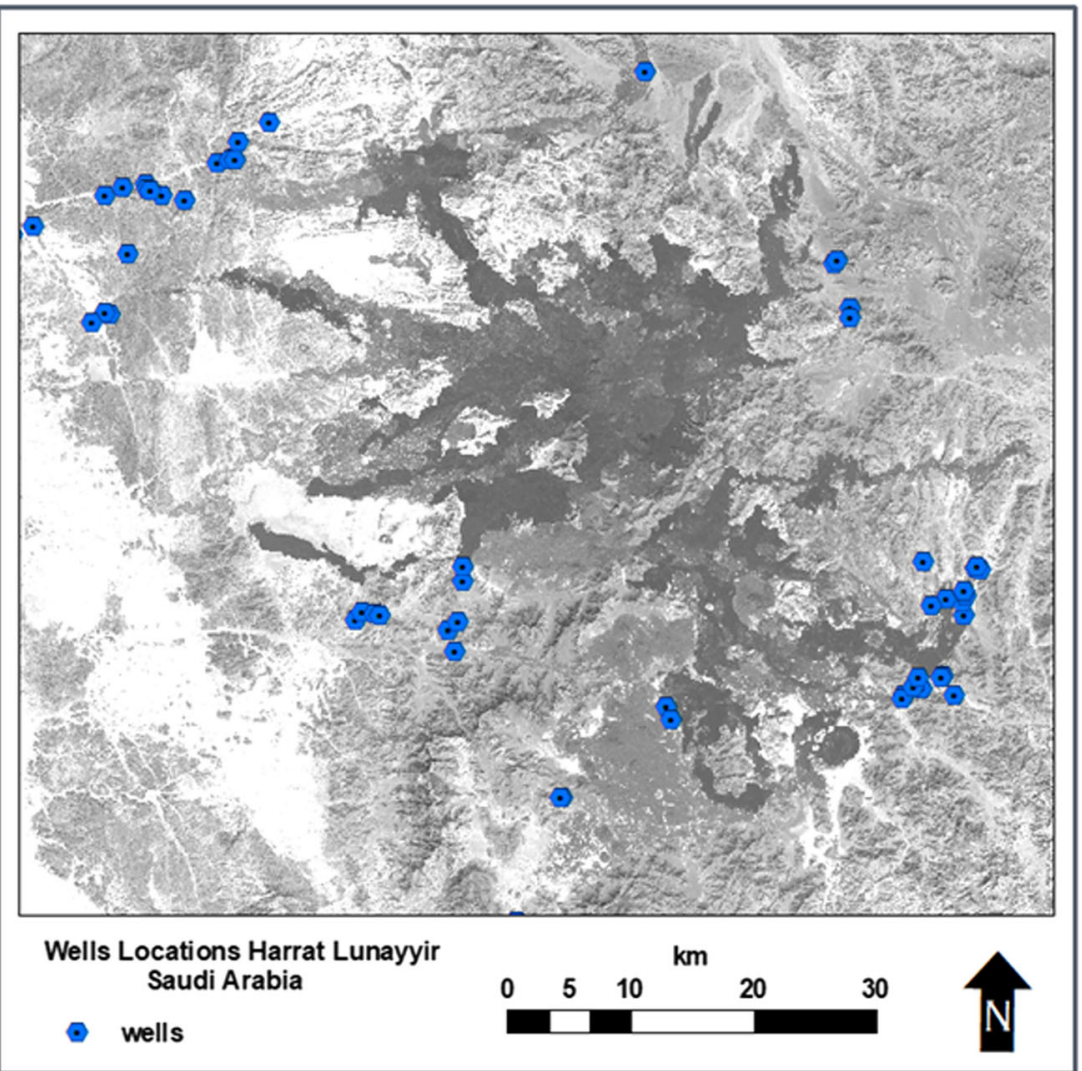


Table 5 Water well depths and temperatures (measured at ground surface level over the period of 2007-2011)

\begin{tabular}{|c|c|c|c|c|c|c|c|c|c|c|c|}
\hline \multirow[t]{3}{*}{ Well } & \multirow[t]{3}{*}{ Depth (m) } & \multicolumn{10}{|c|}{ Temperature $\left({ }^{\circ} \mathrm{C}\right)$} \\
\hline & & \multicolumn{2}{|l|}{2007} & \multicolumn{2}{|l|}{2008} & \multicolumn{2}{|l|}{2009} & \multicolumn{2}{|l|}{2010} & \multicolumn{2}{|l|}{2011} \\
\hline & & Mar & July & Mar & Nov & May & Oct & Jun & Oct & Feb & Sep \\
\hline 1 & 43 & 28.9 & 28.4 & 27 & 28.5 & 28.4 & 27.6 & 26.6 & 28.6 & 28.3 & 28.3 \\
\hline 2 & 53 & 29.5 & 30 & 21.1 & 29.2 & 29.3 & 29.3 & 29.2 & 29.2 & 29.3 & 29.2 \\
\hline 3 & 80 & 29.7 & 30.3 & 30.8 & 30.2 & 30.3 & 30.5 & 29.6 & 30.8 & 30 & 30.5 \\
\hline 4 & 70 & 27.6 & 29.6 & 27.7 & 28.1 & 28.3 & 29.2 & 26.5 & 28.3 & 27 & 28.6 \\
\hline 5 & 43 & 31.3 & 31.8 & 31.3 & 31.7 & 31.8 & 32 & 31.5 & 31.8 & 31.1 & 31.6 \\
\hline 6 & 15 & 27.7 & 30 & 25.3 & 27.6 & 28.8 & 29.7 & 26.5 & 29.4 & 26.4 & 29.5 \\
\hline 7 & 20 & 30.2 & 30.2 & 26.6 & 28.8 & 28.8 & 27.8 & 27.5 & 30 & 27.7 & 29.9 \\
\hline 8 & 19 & 25.1 & 28.4 & 25.4 & 30 & 26.4 & 30.1 & 28.2 & 30.4 & 29.6 & 30.8 \\
\hline 9 & 22 & 30.8 & 31.6 & 28.2 & 29 & 31.4 & 30.4 & 28.2 & 30.4 & 27.3 & 30.8 \\
\hline 10 & 20 & 30.9 & 31.9 & 31.2 & 30.8 & 31 & 31.3 & 29.5 & 31.2 & 31 & 31.2 \\
\hline 11 & 10 & 30.9 & 31.2 & 27.3 & 31.2 & 31.7 & 31.3 & 30.5 & 31.5 & 31.6 & 31.7 \\
\hline 12 & 15 & 30.2 & 29.2 & 25.6 & 27.7 & 28.7 & 28.1 & 26.1 & 28.7 & 26.2 & 28.4 \\
\hline 13 & 15 & 26.7 & 31.2 & 27.2 & 28.6 & 29.3 & 30.5 & 26 & 31.2 & 26.2 & 31.1 \\
\hline 14 & 50 & 28.4 & 29.8 & 24.5 & 29.7 & 29.2 & 29.9 & 29.1 & 30.2 & 29.3 & 30.1 \\
\hline 15 & 49 & 31.3 & 32.7 & 32.1 & 32.5 & 32.8 & 32.6 & 31.9 & 32.9 & 32.5 & 33 \\
\hline 16 & 35 & 32 & 32.6 & 31.5 & 32.5 & 32.2 & 32.5 & 31.6 & 32.8 & 31.9 & 32.7 \\
\hline 1 & 43 & 30.1 & 31.1 & 29.6 & 31 & 30.4 & 31 & 30 & 31.3 & 30.4 & 31.2 \\
\hline 17 & 38 & 32 & 32.9 & 32.3 & 32.4 & 32.6 & 32.7 & 32.3 & 33.1 & 32.3 & 33 \\
\hline 18 & 22 & 22.8 & 26.6 & 25 & 26.6 & 25.9 & 26.5 & 24.6 & 27.9 & 23.5 & 27.2 \\
\hline 19 & 26 & 24.5 & 27.5 & 24.5 & 20.8 & 26.8 & 27.2 & 24.9 & 27.7 & 25.6 & 27.6 \\
\hline 20 & 71 & 29.5 & 29.5 & 29.8 & 29.6 & 30 & 30.4 & 29.4 & 29.5 & 29.8 & 30.6 \\
\hline 21 & 25 & 24.4 & 25.8 & 25 & 25.5 & 25.3 & 25.9 & 24.3 & 26.4 & 24.6 & 26.5 \\
\hline 22 & 26 & 16.9 & 26.4 & 24.8 & 27.3 & 26.1 & 26.6 & 25.4 & 26.9 & 25.6 & 27.1 \\
\hline 23 & 80 & 28 & 28.5 & 27.4 & 29.7 & 28.6 & 28.9 & 27.8 & 29.2 & 28.4 & 29.2 \\
\hline 24 & 22 & 30 & 30 & 29 & 29 & 28.7 & 28.8 & 28.7 & 28.7 & 30.9 & 32.7 \\
\hline 25 & 82 & 23 & 23.5 & 25 & 23.8 & 28.8 & 23.8 & 23.2 & 23.9 & 23.3 & 23.9 \\
\hline 26 & 62 & 30.6 & 30.5 & 27.6 & 30.5 & 30.6 & 30.5 & 30.6 & 28.5 & 30.1 & 30.7 \\
\hline 27 & 70 & 30.2 & 30.5 & 30.5 & 30.5 & 30.4 & 30.5 & 30.5 & 30.5 & 30.7 & 30.7 \\
\hline 28 & 75 & 30.7 & 30.9 & 28.5 & 30.8 & 30.8 & 30.8 & 30.7 & 30.6 & 30.9 & 31.4 \\
\hline 29 & 63 & 30.5 & 30.5 & 30.3 & 30.6 & 30.5 & 30.6 & 30.5 & 30.5 & 30.7 & 30.7 \\
\hline 30 & 70 & 30.7 & 30.5 & 28.9 & 30.7 & 30.6 & 30.5 & 30.5 & 30.2 & 30.7 & 30.5 \\
\hline 31 & 45 & 28.2 & 29.1 & 26.6 & 29 & 29.1 & 29.4 & 28.3 & 29.5 & 28.4 & 29.6 \\
\hline 32 & 35 & 30.1 & 31.5 & 30.2 & 31.4 & 31.8 & 32.1 & 31.8 & 32.2 & 31.5 & 32.4 \\
\hline 33 & 41 & 32.9 & 32.7 & 31.5 & 32.1 & 31.7 & 31.8 & 31.4 & 31.9 & 30.7 & 31.8 \\
\hline 34 & 41 & 31.8 & 32.3 & 29.3 & 32 & 32 & 32.2 & 31.8 & 32.3 & 31.9 & 32.2 \\
\hline 35 & 50 & 32.4 & 33 & 28.8 & 32.7 & 32.1 & 32.6 & 32.6 & 32.3 & 31.8 & 32.8 \\
\hline 36 & 10 & 26.2 & 29.9 & 27.6 & 27.6 & 28.2 & 28.8 & 25.3 & 29.8 & 26.8 & 29.7 \\
\hline 37 & 15 & 31.2 & 31.5 & 25.8 & 27.9 & 28.1 & 28 & 26.6 & 29.5 & 25.5 & 29.4 \\
\hline 38 & 15 & 31.4 & 32.5 & 30 & 29.4 & 32 & 32.4 & 31.5 & 32.1 & 29.6 & 31.3 \\
\hline 39 & 10 & 27.8 & 30.4 & 24.8 & 27.1 & 29.5 & 30.1 & 29.3 & 31 & 28.3 & 30.3 \\
\hline 40 & 20 & 29.5 & 31.5 & 29.3 & 31.1 & 30.1 & 30.7 & 28.2 & 31.9 & 27.6 & 30.9 \\
\hline 41 & 30 & 28 & 29.7 & 25.3 & 28 & 27.5 & 28.5 & 26.8 & 29 & 26.6 & 28.8 \\
\hline 42 & 26 & 29.1 & 29.7 & 27.3 & 30 & 29.3 & 29.6 & 28.2 & 30 & 28 & 29.9 \\
\hline 43 & 30 & 30.6 & 30.6 & 26.6 & 30.1 & 31.5 & 30.7 & 31 & 30.5 & 30.7 & 31.6 \\
\hline 44 & 12 & 28.2 & 30.7 & 22.6 & 29.2 & 29.5 & 29.9 & 26.8 & 31 & 28.3 & 31.4 \\
\hline
\end{tabular}


Table 5 (continued)

\begin{tabular}{|c|c|c|c|c|c|c|c|c|c|c|c|}
\hline \multirow[t]{3}{*}{ Well } & \multirow[t]{3}{*}{ Depth (m) } & \multicolumn{10}{|c|}{ Temperature $\left({ }^{\circ} \mathrm{C}\right)$} \\
\hline & & \multicolumn{2}{|l|}{2007} & \multicolumn{2}{|l|}{2008} & \multicolumn{2}{|l|}{2009} & \multicolumn{2}{|l|}{2010} & \multicolumn{2}{|l|}{2011} \\
\hline & & Mar & July & Mar & Nov & May & Oct & Jun & Oct & Feb & Sep \\
\hline 45 & 40 & 26.2 & 28 & 24 & 37.3 & 28 & 28.4 & 26.8 & 29 & 26.4 & 29.5 \\
\hline 46 & 40 & 28.2 & 29.2 & 25.4 & 28.4 & 28.3 & 29.3 & 27.5 & 29.5 & 27.3 & 30.1 \\
\hline 47 & 30 & 29.2 & 29.3 & 26.8 & 29.3 & 28.6 & 29 & 28.1 & 28.2 & 28 & 28.5 \\
\hline 48 & 20 & 26.6 & 28.5 & 24 & 28.1 & 28 & 28.6 & 28.3 & 29 & 26.9 & 29.1 \\
\hline 49 & 48 & 30.2 & 30.7 & 27 & 29.7 & 30 & 29.9 & 29.1 & 30 & 29.3 & 29.9 \\
\hline 50 & 48 & 27.7 & 27.6 & 25 & 27.7 & 27.7 & 27.6 & 27.6 & 27.7 & 27.8 & 28.1 \\
\hline 51 & 44 & 27.1 & 27.2 & 26 & 27.3 & 27.1 & 27.1 & 26.8 & 27 & 25.7 & 26.9 \\
\hline 52 & 50 & 26.3 & 28.2 & 21.5 & 27.9 & 27.8 & 28 & 26.1 & 32 & 26.2 & 28.5 \\
\hline 53 & 27 & 31.3 & 32.2 & 23 & 29.6 & 29.6 & 29.4 & 27.4 & 30 & 27 & 28.8 \\
\hline 54 & 33 & 27.7 & 24.9 & 20 & 27.9 & 27.8 & 27.9 & 27.4 & 28.5 & 28 & 28.5 \\
\hline
\end{tabular}

temperatures must be introduced to address these factors. This is particularly true for space-borne sensors with large fields of view that conduct regional surveys over ground swaths of hundreds of kilometres or more (Hammerle et al. 2017).

3. Emissivity. This is the ratio of energy emitted from a particular body to that radiated from a perfect emitter (a blackbody) at the same temperature and wavelength (Blackett 2017). The energy emitted by the Earth is related to the temperature and emissivity of the objects or materials within a pixel on the ground (Becker and Liang Li 2009; Galiano et al. 2011). Emissivity quantifies the radiating efficiency of a surface. An object with an emissivity of 1.0 is a perfect emitter, emitting radiation with $100 \%$ efficiency; all other objects emit with less efficiency, with the consequence that the apparent (or radiance) temperature of such objects, if measured remotely, is less than the true kinetic temperature of the object (Blackett 2017) (Vlassova et al. 2014).

In addition to the aforementioned factors, there is a need to account for different explanations for the land surface temperature variation observed via remote sensing data. These temperature variations may be partly due to differences in solar activity and terrain influence. In the case of Harrat Lunayyir, the tectonic activity component can be a residual component after accounting for volcanotectonic activity and terrain influence. The significant scatter pattern of the heat anomalous pixels in the developed surface temperature maps indicates the segmentation of the dyke and forms a linear configuration. The spatial alignment between the volcanic vent and temperature anomalous areas indicates a correlation between the observed thermal variation and volcanotectonic activity, that is, the inferred dyke emplacement.
Another major consideration is the hydrothermal regime of the region. The active geothermal systems are located in the central and southern parts of the Arabian Shield. However, even in the north and north-central parts closer to the Red Sea Rift, active thermal springs have been found (Fig. 13). Based on previous studies (Chandrasekharam et al. 2015, 2016) of the geothermal regime, issuing temperatures associated with these springs are in the range of $31-55^{\circ} \mathrm{C}$ but may reach up to $70{ }^{\circ} \mathrm{C}$ during summer periods. Another geothermal factor contributing to heat anomalies is the high heat input from post-orogenic granites, which are common in the Harrat Lunayyir area. The clusters of heat anomalies located in the outskirts of the Harrat might be the result of heat flow generation due to the process of magma movement at shallower levels.

The map shown in Fig. 14 indicates that the hot water wells in the Lunayyir area are preferentially located along the margins of the basaltic field, but they are typically restricted to the margins of the lava flows. This pattern is in agreement with the regional characteristic of hot springs found in the vicinities of the basaltic fields along the cataclastic zone (Lashin et al. 2015). These hot water wells are characterised by low charge, but individual heat flows may radiate long distances. The maximum depth of the hot wells is $80 \mathrm{~m}$ (Table 5). At this depth, permeable components are likely to include tension fractures and normal faults oriented toward the centre of the field. The hot water wells of this crustal part are also characterised by low resistance as a result of Table 1 . The far-distance heat emanating from the centre of the field that can flow is also reflected in the two mapping datasets (Figs. 8 and 11), with the heat anomalies clustered toward the centre of the field and the hot water wells located alongside the margin. 
Future research objectives highlight the need for a variety of activities, including in situ field studies on bulk emissivity and the thermal inertia of surface cover materials. An empirical analysis of high spectral and spatial resolution imagery is needed to evaluate the utility of thermal infrared measurements for mapping variations in the emissivity of natural surfaces. This is also specifically necessary to evaluate trade-offs between increased resolution and decreased signal-to-noise. In future research, atmospheric effects can be accounted for within localised areas through the use of upward-viewing, ground-based radiometers.

\section{Conclusions}

The current study examined the relationship between the relative changes in surface temperatures 'LST' and seismic-tectonic activities and provided new insights into the spatiotemporal relationship between volcanic and tectonic processes in the area. Through the employment of the methodology of thermal mapping and spatial density mapping of volcanic vents (primarily crater cones and small lava shields), the land surface temperature changes in the centre of Harrat Lunayyir were recorded when the 2009 dyke was propagating toward the surface. The obtained results are in agreement with previous research findings indicating the northwest-southeast direction of the dyke system and the normal fault formation.

This paper focused on monitoring and estimating relative changes in surface temperatures as a means for detecting an impending dyke-fed eruption or, alternatively, dyke arrest at a shallow depth, which consequently provides an understanding of the point at which a particular hazard event ('fissure eruptions') is most likely to occur. This provides critical information that supports disaster responders and emergency management. Consequently, this helps provide the foundation for response prioritisations, disaster assessment, informed mitigation planning, and thorough risk assessments. Therefore, infrared observations may increase understanding about a volcano's activity status and reveal incoming changes in activity.

A strong correlation was found between dyke intrusion and LST. The variety of surface temperature values in the past several years based on the thermal energy response. Consequently, this study was beneficial in that it can help protect the lives of those residing close to danger zones by suggesting necessary courses of action to take before a disaster occurs in the future.

Acknowledgements AAS thanks Morayyea Al-Shahrani, President of the General Commission of Survey for the helpful suggestions. She also thanks Abdullah Al-Amri Adel Alsharif, Basim al Dahri, Maher Al Dahry, Ali Al Shehri, and Numan Muhammd for various helpful suggestions and information in connection with this work.
Open Access This article is distributed under the terms of the Creative Commons Attribution 4.0 International License (http:// creativecommons.org/licenses/by/4.0/), which permits unrestricted use, distribution, and reproduction in any medium, provided you give appropriate credit to the original author(s) and the source, provide a link to the Creative Commons license, and indicate if changes were made.

\section{References}

Al Shehri A, Gudmundsson A (2018) Modelling of surface stresses and fracturing during dyke emplacement: application to the 2009 episode at Harrat Lunayyir, Saudi Arabia. Volcanol Geotherm Res 356: 278-303

Al-Amri AM, Al-Mogren SM (2011) Seismo-volcanic investigation of the current activity in Harrat Lunayyir, Al-Madinah AlMunawwarah area. Final report. King Saud University, Riyadh, pp $1-184$

Al-Amri A, Fnais M (2009) Seismo-volcanic investigation of 2009 earthquake swarms at Harrat Lunayyir (Ash Shaqah), Western Saudi Arabia. Int J Earth Sci Eng, October issue, 1-18.

Al-Amri A, Fnais M, Abdel-Rahman K, Mogren S, Al-Dabbagh M (2012) Geochronological dating and stratigraphic sequences of Harrat Lunayyir, NW Saudi Arabia. Int J Phys Sci 7:2791-2805. https://doi.org/10.5897/IJPS12.178

Alberico I, Petrosino P, Lirer L (2010) Volcanic hazard and risk assessment in a multi-source volcanic area: the example of Napoli city (Southern Italy). Nat Hazards Earth Syst Sci 11:1057-1070. https://doi.org/10.5194/nhess-11-1057-2011

Al-Zahrani H, Al-Amri AM, Abdel-Rahman K, Fnais M (2013) Aftershock sequence analysis of 19 May 2009 earthquake of Lunayyir lava flow, northwest Saudi Arabia. Int J Phys Sci 8:277285

Baer G, Hamiel Y (2010) Form and growth of an embryonic continental rift: InSAR observations and modelling of the 2009 western Arabia rifting episode. Geophys J Int 182:155-167

Bailey G (2009) The Red Sea, coastal landscapes and hominin dispersals. In: Petraglia MD, Rose JI (eds) The evolution of human populations in Arabia. Springer, Dordrecht, pp 15-37

Barnie T, Oppenheimer C (2015) Extracting high temperature event radiance from satellite images and correcting for saturation using independent component analysis. Remote Sens Environ 158:56-68

Becker F, Liang Li Z (2009) Surface temperature and emissivity at various scales: definition, measurement and related problems. Remote Sens Rev 12:225-253

Blackett M (2017) An overview of infrared remote sensing of volcanic activity. J Imaging 3:13. https://doi.org/10.3390/jimaging3020013

Boya L (2004) The thermal radiation formula of Planck (1900). Universidad de Zaragoza, Zaragoza

Chandrasekharam D, Lashin A, Al Arifi N, Al Bassam AA, Varun C (2015) Evolution of geothermal systems around the Red Sea. Environ Earth Sci 73(8):4215-4236

Chandrasekharam D, Lashin A, Al Arifi N, Al-Bassam AM (2016) Red Sea geothermal provinces. CRC Press

Da Wen C (2010) Investigation of steel emissivity behavior: examination of multispectral radiation thermometry emissivity models. Int J Heat Mass Transf 53:2035-2043

Galiano R, Igúzquiza P, Olmo C, Sánchez R (2011) Increasing the spatial resolution of thermal infrared images using cokriging. Procedia Environ Sci, Elsevier 3:117-122

Genna A, Nehilg P, Le Goff E, Guerrot C, Shanti M (2002) Proterozoic tectonism of the Arabian Shield. Precambrian Res 117:21-40

Gudmundsson A (2002) Emplacement and arrest of sheets and dykes in central volcanoes. J Volcanol Geotherm Res 116:279-298 
Gudmundsson A (2003) Surface stresses associated with arrested dykes in rift zones. Bull Volcanol 65:606-619

Gudmundsson A (2011a) Deflection of dykes into sills at discontinuities and magma-chamber formation. Tectonophysics 500:50-64

Gudmundsson A (2011b) Rock fractures in geological processes. Cambridge University Press, Cambridge

Gudmundsson A (2019) Volcanotectonics: understanding the structure, deformation, and dynamics of volcanoes. Cambridge University Press, Cambridge

Hammerle A, Meier F, Heinl M, Egger A, Leitinger G (2017) Implications of atmospheric conditions for analysis of surface temperature variability derived from landscape-scale thermography. Int J Biometeorol 61:575-588

Hansen E, Puckett E, Keller R, Brueseke E, Bulen L, Mertzman A, Finegan A, McCleery A (2013a) Intra-plate magmatism related to opening of the southern Iapetus Ocean: Cambrian Wichita igneous province in the Southern Oklahoma rift zone. Lithos. 174:57-70

Hansen E, DeShon R, Driskell M, Al-Amri M (2013b) Investigating Pwave velocity structure beneath Harrat Lunayyir, north western Saudi Arabia, using double-difference tomography and earthquakes from the 2009 seismic swarm. J Geophys Res 118:4814-4826

Harris A (2013) Thermal remote sensing of active volcanoes: a user's manual. Cambridge University Press, Cambridge 736

Harris L, Blake S, Rothery A, Stevens F (1997) A chronology of the 199 to 1993 Etna eruption using AVHRR data: implications for real time thermal volcano monitoring. J Geophys Res 102:7985-8003

Haselwimmer C, Prakash A (2013) Thermal infrared remote sensing of geothermal systems. Remote Sens Digit Image Process 17:453-473

IUCN (2009) In: IUCN (ed) World Heritage Volcanoes, Gland 70

Jensen J (2007) Remote sensing of the environment: an Earth resource perspective, 2nd edn. Pearson Prentice Hall, Upper Saddle River

Jónsson, S., Pallister, J., McCausland, W., El-Hadidy, S., 2010. Dyke Intrusion and Arrest in Harrat Lunayyir, western Saudi Arabia, in April-July 2009. Geophysical Research Abstracts, 12, 7704.

Kavanagh J, Burns A, Hazim S, Wood E, Martin S, Hignett S, Dennis D (2018) Challenging dyke ascent models using novel laboratory experiments: implications for reinterpreting evidence of magma ascent and volcanism. Volcanol Geotherm Res 354:87-101

Koulakov I, El Khrepy S, Al Arifi N, Sychev I, Kuznetsov P (2014) Evidence of magma activation beneath the Harrat Lunayyir basaltic field (Saudi Arabia) from attenuation tomography. Solid Earth 5: 873-882

Koulakov, I., El Khrepy, S., Al-Arifi, N., Kuznetsov, P., \& Kasatkina, E., (2015) Structural cause of a missed eruption in the Harrat Lunayyir basaltic field (Saudi Arabia) in 2009. Geology. 43:395-398

Lashin A, Al Arifi N, Chandrasekharam D, Al Bassam A, Rehman S, Pipan M (2015) Geothermal energy resources of Saudi Arabia: country update. In Proceeding, World Geothermal Congress

Moran C, Newhall C, Roman C (2011) Failed magmatic eruptions: latestage cessation of magma ascent. Bull Volcanol 73:115-122

Mukhopadhyay B, Mogren S, Mukhopadhyay M, Dasgupta S (2013) Incipient status of dyke intrusion in top crust- evidences from the Al-Ays 2009 earthquake swarm, Harrat Lunayyir, SW Saudi Arabia. Geomat Nat Haz Risk 4:30-48

Murphy W, Wright R, Oppenheimer C, Souza Hilho R (2013) MODIS and ASTER synergy for characterizing thermal volcanic activity. Remote Sens Environ 131:195-205

NASA (2018) Landsat 7 science data users handbook. Nasa.Gov

Noguchi T, Ohno N, Hattori K, Oyama K (2011) Detection of thermal changes possibly associated with volcanic activity and discrimination of faint changes from MODIS. J Asian Earth Sci 41:467-475
Oppenheimer C, Yirgu G (2002) Thermal imaging of an active lava lake: Erta 'ale volcano, Ethiopia. Int J Remote Sens 23:4777-4782

Pallister J, McCausland W, Jónsson S, Lu Z, Zahran H, El-Hadidy S, Aburukbah A, Stewart I, Lundgern P, White R, Moufti M (2010) Broad accommodation of rift-related extension recorded by dyke intrusion in Saudi Arabia. Nat Geosci 3:705-712

Paulsen T, Wilson T (2009) Structure and age of volcanic fissures on Mount Morning: a new constraint on Neogene to contemporary stress in the West Antarctic Rift, southern Victoria Land, Antarctica. Geol Soc Am 121:7-8

Pyle D, Mather T, Biggs J (2015) Remote sensing of volcanoes and volcanic processes: integrating observation and modelling - introduction. Remote Sensing of Volcanoes and Volcanic Processes: Integrating Observation and Modelling. Geol Soc Lond Spec Publ 380:1-13

Ramsey MS, Flynn LP (2004) Strategies, insights, and the recent advances in volcanic monitoring and mapping with data from NASA's Earth Observing System. J Volcanol Geotherm Res 135(1-2):1-11

Realmuto J, Worden M (2000) The impact of atmospheric water vapor on the thermal infrared remote sensing of volcanic sulfur dioxide emissions: a case study from the Pu'u 'O'o vent of Kilauea Volcano, Hawaii. J Geophys Res 21:497-421

Rivalta E, Taisne B, Bunger P, Katz F (2015) A review of mechanical models of dyke propagation: schools of thought, results and future directions. Sci. Direct. Tect Phys 638:1-42. https://doi.org/10.1016/ j.tecto.2014.10.003

Sobrino JA, Jiménez-Muñoz JC, Sòria G, Romaguera M, Guanter L, Moreno J, Plaza A, Martínez P (2008) Land surface emissivity retrieval from different VNIR and TIR sensors. IEEE Trans Geosci Remote Sens 46(2):316-327

Townsend R, Pollard D, Smith P (2017) Mechanical models for dikes: a third school of thought. Tectonophysics. 703-704:98-118

Tralli D, Blom R, Zlotnicki V, Donnellan A, Evans D (2005) Satellite remote sensing of earthquake, volcano, flood, landslide and coastal inundation hazards. ISPRS J Photogramm Remote Sens 59:185198

van der Zwan FM, Augustin N, Devey CW, Bantan R, Kwasnitschka T (2013) New insights into volcanism and tectonics in the Red Sea Rift. Geophys Res Abstr 15:EGU2013-7188 EGU General Assembly

Vaughan G, Hook J, Ramsey S, Realmuto J, Schneider J (2005) Monitoring eruptive activity at Mount St. Helens with TIR image data. Geophys Res Lett 32:1-4

Vlassova L, Pérez-Cabello F, Mimbrero MR, Llovería RM, GarcíaMartín A (2014) Analysis of the relationship between land surface temperature and wildfire severity in a series of Landsat images. Remote Sens 6(7):6136-6162

Wellons M (2007) The Stefan-Boltzmann law. Physics Department, The College of Wooster, Wooster

Xu W, Jonsson S, Corbi F, Rivalta E (2016) Graben formation and dike arrest during the 2009 Harrat Lunayyir dike intrusion in Saudi Arabia: insights from InSAR, stress calculations and analog experiments. J Geophys Res 121. https://doi.org/10.1002/2015JB012505

Zahran M, Mccausland A, Pallister S, Lu Z, El-hadidy S, Aburukba A, Schawali J, Kadi K, Youssef A, Ewert W, White A, Lundgren P, Mufti M, Stewart C (2009) Stalled eruption or dike intrusion at Harrat Lunayyir, Saudi Arabia? Am Geophys Union 13:E-2072

Zobin V, Al-Amri A, Fnais M (2013) Seismicity associated with active, new-born and re-awakening basaltic volcanoes: case review and the possible scenarios for the Harrat volcanic provinces, Saudi Arabia. Arab J Geosci 6:529-541 